\title{
Evaluating the efficacy of small-scale MPAs for preserving reef health: A case study applying emerging monitoring technology
}

\section{Authors:}

D.T.I. Bayley ${ }^{1,2,3}$, A.O.M. Mogg ${ }^{4}$, A. Purvis ${ }^{1,5}$, and H.J. Koldewey ${ }^{3,6}$

Affiliations:

1. Department of Life Sciences, Natural History Museum, Kensington, London, SW7 $5 \mathrm{BD}, \mathrm{UK}$.

2. Centre for Biodiversity and Environment Research, University College London, London, WC1H 0AG, UK

3. Zoological Society of London, Regent's Park, London, NW1 4RY, UK

4. National Facility for Scientific Diving, Scottish Association of Marine Sciences, Oban, PA37 1QA, UK

5. Department of Life Sciences, Imperial College London, Silwood Park campus, Ascot SL5 7PU, U.K.

6. Centre for Ecology and Conservation, University of Exeter, Penryn Campus, Penryn, Cornwall, TR10 9FE, UK

Correspondence:

Dan Bayley: Daniel.bayley.14@ucl.ac.uk

Keywords:

MPAs, Community structure, complexity, fisheries, management, reefs, blast fishing, photogrammetry

\footnotetext{
Abstract

1. Marine Protected Areas (MPAs) are widely used as management tools to conserve species and ecosystems at risk from human impact. Coastal managers often focus MPA designation on biogenic reef environments due to their value and sensitivity to damage. However, difficulties in enforcement and a lack of capacity to adequately monitor MPAs often make it hard for managers to assess the effectiveness of MPAs, particularly in under-resourced, low-income coastal countries.

2. Reef community data were collected at three long-term managed reserves within the Western Visayas region of the central Philippines in order to assess the state of reef community structure inside and outside of these small-scale locally managed MPAs. In addition, 3D structural data were captured using recently developed 'Structure from Motion' (SfM) photogrammetry techniques, demonstrating how multiple quantitative metrics of physical structural complexity and health can be recorded in such analyses.
} 
3. These community-run MPAs were shown to be effective even when small (10-20 ha). Mean fish biomass density was five times greater within present-day protected sites, alongside significantly increased levels of fish diversity, richness, and size. No significant structural differences were observed inside and outside of MPAs, however, average reef rugosity, height, and roughness were significantly higher in unfished reefs compared to blast-fished reefs. Reef substrate complexity, coral composition, and level of management, were also shown to structure fish community assemblages, with the link between reef structure and fish richness / abundance disrupted outside of MPAs.

4. The SfM technique allows a greater range of quantitative morphometrics to be assessed than traditional methods and at relatively low cost. The technique is rapid, non-destructive and can be archived, increasing the value of data for managers wishing to quantify reef health and efficiently monitor benthic changes through time. We discuss both the limitations and benefits of this technology's future use.

\section{Introduction}

Human activity is having a global negative impact on species and habitats across both terrestrial and aquatic ecosystems (Butchart et al., 2010; Mora et al., 2011). The world's oceans in particular have been heavily degraded, primarily due to anthropogenic changes in global levels of land-based pollution, over-extraction of resources, and changing environmental conditions (Halpern et al., 2015; Maxwell, Fuller, Brooks, \& Watson, 2016). In response to these multiple mounting pressures on ocean systems, marine protected areas (MPAs) are increasingly being used as a management mechanism to mitigate fishing damage and conserve individual species or entire systems at risk (Lester et al., 2009; Pimm, 2001; Roberts et al., 2017). Globally agreed targets now aim for at least $10 \%$ of the oceans to be protected through well-enforced MPAs by 2020 (Thomas et al., 2014), and still more may be needed for effective protection (O'Leary et al., 2016; Sciberras, Jenkins, Kaiser, Hawkins, \& Pullin, 2013). Tropical coastal managers often apply MPA management to coral reefs due to the importance of this habitat type for associated species (Cole, Pratchett, \& Jones, 2008; Paulay, 1997), as well as for the ecosystem services that reefs provide through food provision and tourism, and their sensitivity to disturbances such as fishing (McClanahan, Marnane, Cinner, \& Kiene, 2006; Tamayo, Anticamara, \& Acosta-Michlik, 2018).

MPAs can be highly effective in reef environments if designed and managed correctly (Lester et al., 2009; Roberts et al., 2017); however, there are still frequent disagreements over the extent of MPAs' socio-economic benefits, their optimal size, number and location (Edgar et al., 2014; Hargreaves-Allen, Mourato, \& Milner-Gulland, 2017; Kaiser, 2005; Singleton \& Roberts, 2014), and even whether apparent biotic benefits arise from changed animal behaviour rather than true diversity change (Langebrake, Riotte-Lambert, Osenberg, \& de Leenheer, 2012). Alongside these concerns, uncertainty remains over the timescales over which managers can see tangible results and the best ways in which to objectively measure and record change (Hudson et al., 2014; McClanahan et al., 2006; Mouillot et al., 2016). Discussions commonly focus on whether a more integrated 'holistic' approach to management is needed, and whether management is currently enforced sufficiently to prevent these areas simply being 'paper parks', existing only on maps (Agardy, di Sciara, \& Christie, 2011; Gill et al., 2017; Mora et al., 2006; Riegl, Bruckner, Coles, Renaud, \& Dodge, 2009). Underlying many of these discussions is the frequent inability of managers to quantitatively capture objective measures of a reef's current or historical state, particularly in low-income 
countries whose limited resources and high dependence on reef services place their reefs at high risk of degradation (Gill et al., 2017; Marinesque, Kaplan, \& Rodwell, 2012).

A case study is presented comparing surveys of reef structure and fish communities inside and outside a set of small, locally managed MPAs within the Visayas region of the central Philippines. In this region in the heart of the 'Coral triangle', reefs are an essential component to local people's livelihoods, but are also subject to a range of chronic and acute pressures, in the form of overfishing, destructive fishing techniques such as 'blast fishing', and earthquake / storm damage (Magdaong et al., 2014; Samoilys et al., 2007; Selgrath, Gergel, \& Vincent, 2017). Blast fishing in particular is known to be extremely damaging to coral reefs and leads to long-term effects on benthic community dynamics (Fox \& Caldwell, 2006). Despite the practice being both dangerous and illegal, the short-term economic gains have led to its use being widespread in the Philippines since the 1930s, resulting in extensive damage to the benthos and fisheries in this region (Alcala \& Russ, 2002).

The resilience of reefs to degradation and community phase shifts following disturbance is bolstered by a number of key ecosystem attributes, which include structural complexity, depth, high densities of both juvenile corals and herbivorous fishes, and low nutrient loads (Graham, Jennings, MacNeil, Mouillot, \& Wilson, 2015). High structural complexity in particular seems to be integral to a number of ecological functions and services (Graham \& Nash, 2013; Perry et al., 2018): complex reefs provide food and habitat for many species, resulting in higher fish density and biomass (Graham \& Nash, 2013), shape fish community structure (Darling et al., 2017), and influence predator-prey behavioural dynamics (GonzálezRivero et al., 2017).

While the physical 3D complexity of a reef is often highlighted as being important to its functioning, it is typically either measured inadequately (due to time and technology constraints) or even overlooked in health assessments. Linear surface 'rugosity' (sensu Luckhurst and Luckhurst 1978) is the most commonly used measurement, but is inherently sensitive to subjective choices of placement, is non-repeatable, and can be highly variable in the scale of assessment, replication and accuracy. Other more qualitative visual assessments (reviewed in Wilson et al., 2007) avoid some of these problems but are still subjective and often cannot be directly re-assessed or validated for that point in time as they are conducted in situ.

Recent advances in technology and computing power have allowed the development of new techniques for more detailed and objective recording of reef morphometrics (Bayley \& Mogg, 2019). One such technique - termed 'Structure from Motion' stereo-photogrammetry (SfM) - allows detailed scaled 3D digital models of the reef to be created over large areas (from above or below water), using multiple overlapping imagery (Burns, Delparte, Gates, \& Takabayashi, 2015; Westoby, Brasington, Glasser, Hambrey, \& Reynolds, 2012). This technique has been shown to be both accurate and repeatable at a range of scales underwater and is therefore rapidly gaining popularity as a reef survey tool (Bayley, Mogg, Koldewey, \& Purvis, 2019; Bryson et al., 2017; Ferrari et al., 2016; Figueira et al., 2015; GutierrezHeredia, Benzoni, Murphy, \& Reynaud, 2016; House et al., 2018; Lavy et al., 2015; Raoult, Reid-Anderson, Ferri, \& Williamson, 2017). Alongside the utility to create 3D models, SfM further allows users to create large-scale ortho-rectified photo-mosaics in high definition, enabling both spatial and compositional analysis of coral communities (Edwards et al., 2017).

In this study, SfM photogrammetry was combined with standard benthic and demersal fish monitoring surveys to document the state of the coral reef and reef-associated fish inside and outside of three Philippine MPAs and this localized case study was used to show how this 
emerging method can usefully be applied to estimate the effects of pressures and management on reefs.

\section{Materials and Methods}

\section{Location}

Surveys were carried out in November 2016 at four locations along the western extent of the Danajon Bank reef system, north of Bohol, Philippines (Figure 1). The double barrier reef system covers a total area of $271.7 \mathrm{~km}^{2}$ and encompasses three major provinces of the Philippines (Cebu, Bohol and Leyte). Reefs were assessed inside and outside of three community-managed MPAs (Batasan, Bilang-bilangan and Pandanon) and at an un-managed control site within the same inner barrier reef flat system (Canlangi).

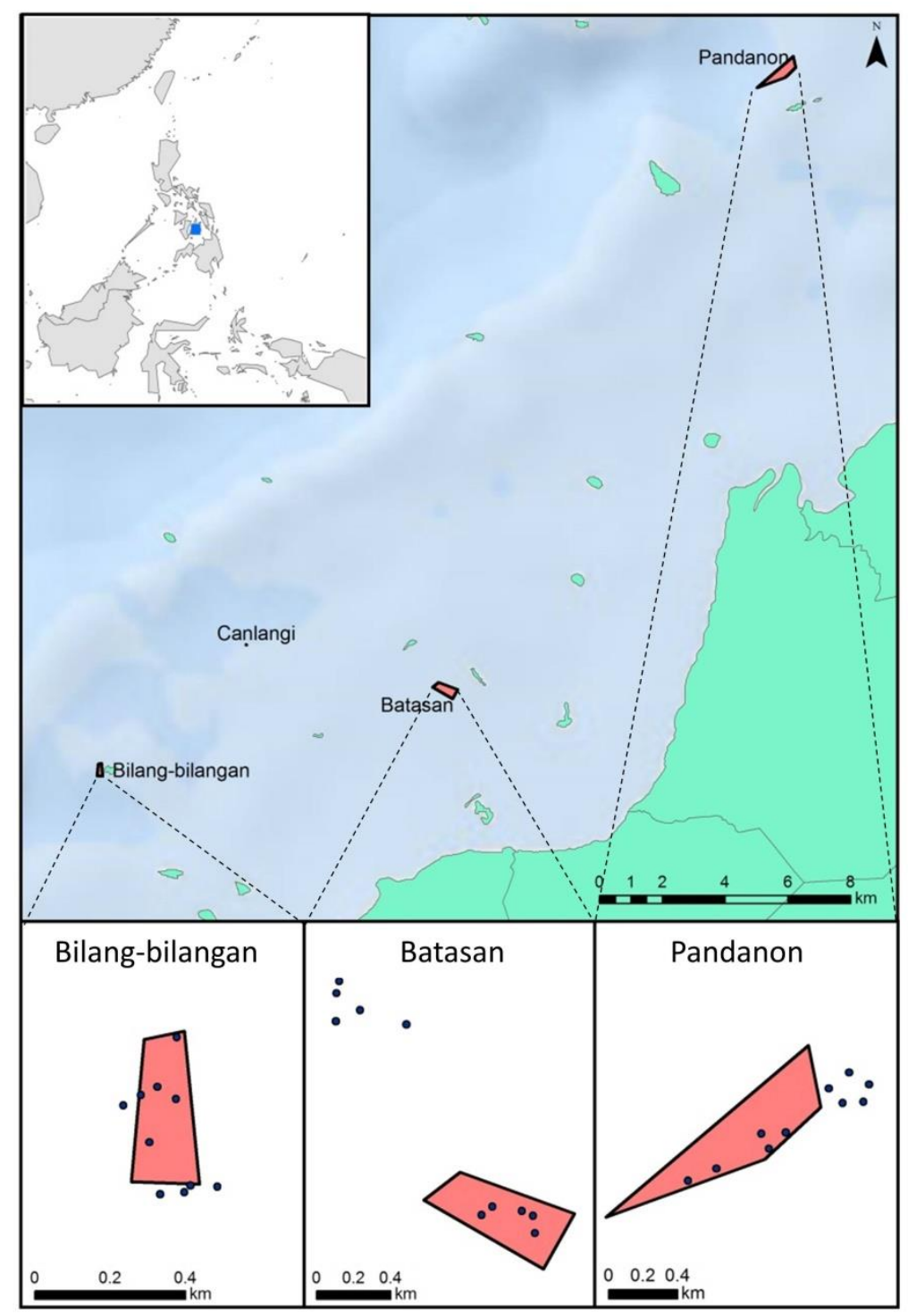

Figure 1. Location of the three MPA boundaries and individual site stations (shown with points) surveyed in 2016 within the Danajon Bank reef system, Philippines. The control site (Canlangi) is also marked. 


\section{Level of impact/compliance}

The sites range in their age and size, but are all small in area ( 16 - 33 ha). MPA distances to the shore of Bohol are between 6 and $9 \mathrm{~km}$ and general reef conditions are comparable across sites. Major reef pressures from blast fishing and recent (2013) earthquake damage varied from low to high across the three MPA sites, although all have high community engagement and have been locally managed for close to two decades (Table 1).

Table 1. Characteristics of the three MPAs along the Danajon Bank reef system, including measures of management and compliance based on (Alcala, Bucol, \& Nillos-kleiven, 2008; Yasué, Nellas, \& Vincent, 2012). The Coastal Conservation \& Eductation Foundation (CCEF) management scoring system ranges from 0 (lowest) to 40 (highest). *Refer to (White et al., 2006) for further details of score calculation and grading.

\begin{tabular}{|c|c|c|c|c|c|c|}
\hline MPA name & $\begin{array}{l}\text { Year } \\
\text { est. }\end{array}$ & $\begin{array}{l}\text { Total } \\
\text { size } \\
\text { (ha) } \\
\end{array}$ & $\begin{array}{l}\text { CCEF } \\
\text { score }(0- \\
40)^{*}\end{array}$ & CCEF description* & Blasting & Earthquake \\
\hline $\begin{array}{l}\text { Bilang - } \\
\text { Bilangan }\end{array}$ & 1999 & 15.5 & 39 & $\begin{array}{l}\text { 'Enforced' and good } \\
\text { management } \\
\text { 'Institutionalized' and }\end{array}$ & None & No \\
\hline Batasan & 1999 & 21 & 38 & $\begin{array}{l}\text { excellent management } \\
\text { 'Enforced' and good }\end{array}$ & Low & Yes \\
\hline Pandanon & 2002 & 33.1 & 34 & management & High & No \\
\hline
\end{tabular}

In 2011 the Philippines changed their system for rating the effectiveness of MPAs to the 'Management Effectiveness Assessment Tool' (MEAT), and in 2015 all three sites scored 4950 (of a maximum 84 points), inferring 'very good management' (Cabral et al., 2014); however, the previous Coastal Conservation \& Education Foundation (CCEF) system was used in this study for consistency over a longer period of assessment. CCEF scores can range in value from 0 to 40 (based on periodic assessments of enforcement, monitoring, local community participation, planning and economic viability of the MPA (White, Alino, \& Meneses, 2006).

Unprotected areas across the region are subject to fishing pressure from multiple gear types (including 'blast fishing; fish corrals; gleaning; hook-and-line; nets; poison fishing; skin diving; and traps'), which target a mixed-species fishery, primarily exploited for local subsistence use (Selgrath et al., 2017).

\section{Bilang-Bilangan (Low impact area)}

This site has had ongoing MPA management since 1999, with biannual (wet and dry season) or annual benthic and demersal community monitoring since 2001 and periodic CCEF management assessments. The management score is currently very high (Table 1), but was at an initial value of 22 following the first CCEF assessment in 2006 (White et al., 2006). There was only minor recorded damage to these reefs following the 2013 earthquake aside from some island subsidence, and no blast fishing was observed during the survey or in discussion with local managers. 


\section{$\underline{\text { Batasan (Moderate impact area) }}$}

This site has had ongoing management protecting the MPA since 1999, with biannual or annual benthic and demersal community monitoring since 2001, and periodic CCEF management assessments. The management score has been consistently high due to good enforcement and compliance (Table 1), noting, however, that the last CCEF management assessment was in 2010. Heavy damage was experienced in this area following the 7.2magnitude earthquake that hit central Bohol in late 2013, with large fissures and cracks forming. From discussions with local fisherman and from observations whilst surveying, there are also currently low levels of blast fishing occurring in the area.

\section{$\underline{\text { Pandanon (High impact area) }}$}

This site has had ongoing management protecting the MPA since 2002 with biannual benthic and demersal community monitoring and periodic CCEF management assessments. However, the site was severely damaged by blast fishing previous to management implementation, with many sites already predominantly rubble. Current MPA enforcement is classed as 'good' (Table 1), but was historically poorer with an initial score of 25 in 2006 under the CCEF scoring system. Reefs in the surrounding area are, however, very poorly managed and still heavily impacted by blast fishing and occasional cyanide fishing. During survey, regular blast fishing activity was observed in the local vicinity (blasts heard roughly every 30 minutes), with typical activity anecdotally more frequent and more localized from discussions with village fishers. The extent of any earthquake damage is unknown due to the site already being extensively damaged, but no fissures or obvious earthquake signs were observed from monitoring reports and the site is further from the epicentre than the other two sites.

\section{Canlangi (Control site / unmanaged area)}

This area lies within the same reef type and impact area as the three MPA study sites, but has no management in place currently or historically. This region experiences a range of fishing types, and visual evidence of low-level blast fishing and net fishing was seen across the area surveyed.

\section{Data collection and processing}

Thirty-five survey stations were analysed across the four site locations for their benthic physical and community structure and associated fish community structure (Figure 1). Ten replicate surveys were conducted for each MPA site (five inside managed areas and five in close proximity outside the managed areas), with a further five surveys conducted in a comparable but unprotected control site in the same reef system. All reef surveys were structured in a stratified random design, and were conducted in the daytime during November 2016 at depths of 5 to 8 metres. Visibility ranged from clear $(>10 \mathrm{~m})$ to moderately turbid $(>5$ $\mathrm{m}$ ), with a minimum survey cut-off of $5 \mathrm{~m}$ horizontal visibility to ensure accurate fish assessments and benthic photography.

\section{$\underline{\text { Benthos }}$}

Using the location of the fish observer as a central point, benthic surveys were conducted after each fish census to digitize a planar area of reef covering $>25 \mathrm{~m}^{2}$. Following (Burns et al., 2015), each whole quadrat was imaged across its full area in a boustrophodonic pattern at 
$\sim$ 1-2 metres above the substrate (dependent on visibility). A single diver used a Nikon D750 DSLR camera (with a wide-angle fixed lens and dome port) for all imaging, to capture high detail ( 6016 x 4016 px) images and prevent any potential variation between resulting models caused by use of differing camera or lens types (as highlighted in Lavy et al. 2015). A digital surface model of the area photographed was then created using 'Photoscan Professional' software (Agisoft LLC, 2017). Each individual model used between 300 - 400 overlapping digital photographs, depending on the ambient light levels and benthic topography. Following calibration to multiple in-situ marker points of known dimensions in xyz space, the reefscape point clouds were clipped and aligned to a 5 x 5 metre square area, and exported for analysis of multiple structural complexity metrics within Gwyddion freeware (Nečas \& Klapetek, 2012), following a process of rasterization with linear interpolation (Figure 2). Surface models (PLY format) of all reefs used in this analysis are freely available from an online repository (http://morphosource.org/Detail/ProjectDetail/Show/project_id/437). For more detail on the process of creating SfM-derived reef models, and the range of applications, see (K. Anderson, Westoby, \& James, 2019; Bayley et al., 2019; Ferrari et al., 2016).

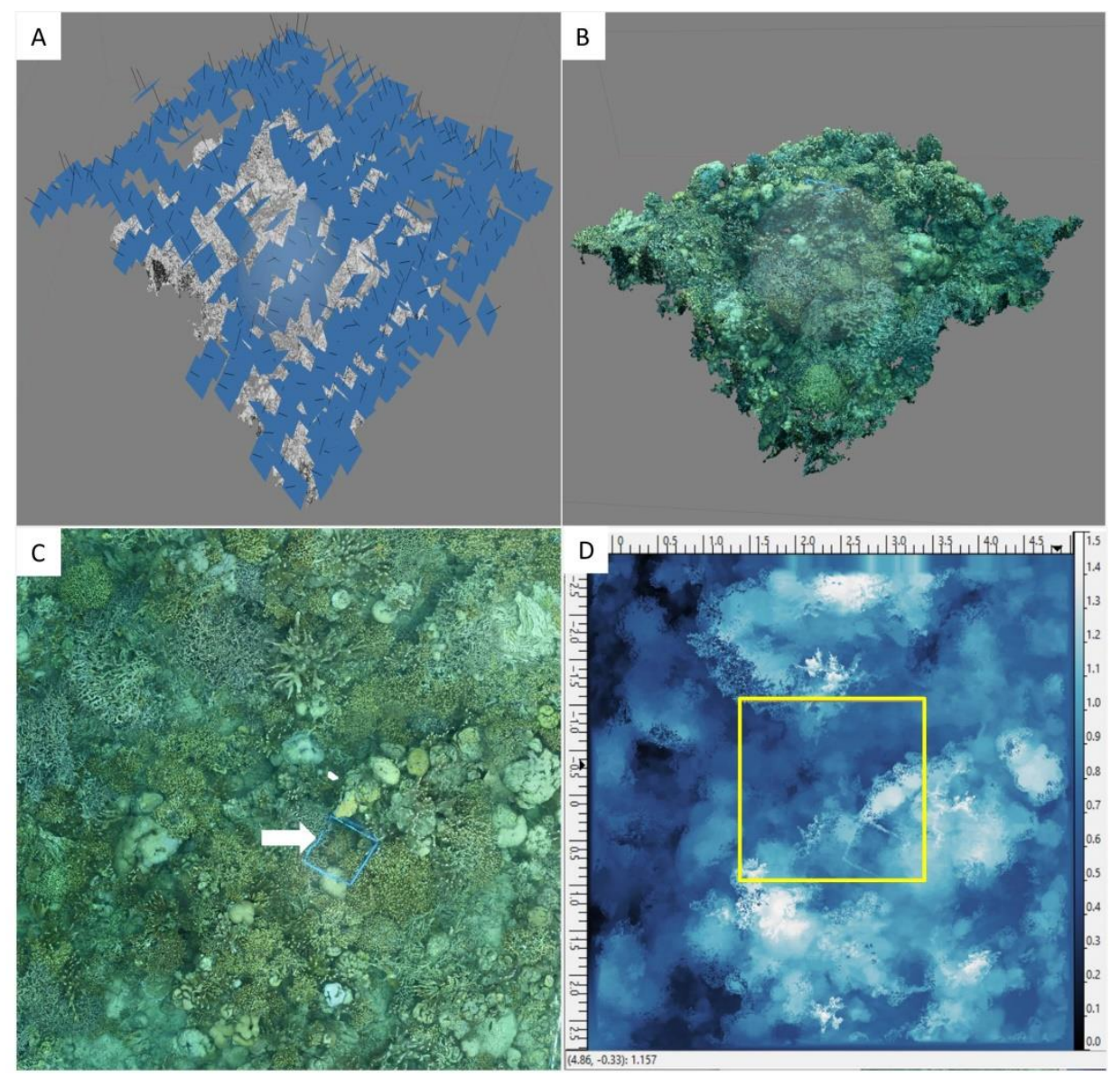

Figure 2. Typical SfM process and 3D outputs from a site in Batasan, Philippines, illustrating (A) the initial dense point-cloud, with individual camera locations shown; (B) TIN mesh with draped colour imagery; (C) a high definition ortho-rectified image mosaic of a 5 x 5 metre reef area, with in-situ blue quadrat $(0.5 \times 0.5 \mathrm{~m})$ shown centre with white arrow; and (D) a calibrated XYZ point-cloud with a virtual $2 \times 2$ metre quadrat illustrated in the centre. 


\section{$3 D$ structural metrics}

Nine reef surface sub-samples were taken across five $(5 \times 5 \mathrm{~m})$ reef digital models, with each sub-sample covering a planar area of $1 \mathrm{~m}^{2}$, and a gap of 1 metre between each sample, giving a total of 45 replicates per management type (IN / OUT of MPA) per site. Four metrics of 3D structure were assessed: 3D rugosity, defined as 3D surface area / 3D projected area $\left(1 \mathrm{~m}^{2}\right)$; height difference, defined as the difference between the maximum and minimum ' $Z$ ' depth values of each surface; RMS variation, defined as the root mean squared variation of the $\mathrm{Z}$ height irregularities from a central plane through the surface; and kurtosis, the positive or negative spikiness or bend of the surface, computed from 4th central moment of data values. Further detail on each metric is available from Gwyddion (Klapetek, Necas, \& Anderson, 2016)

\section{Broad substrate cover metrics}

Broad substrate type has been shown to strongly influence associated fish community structure (Richardson, Graham, \& Hoey, 2017). SfM was used to produce high definition scaled planar ortho-mosaic photo images of each $25 \mathrm{~m}^{2}$ sample area from the 2016 benthic surveys. The stitched image was then assessed for percentage cover of eight broad substrate classes (live coral, dead coral / rock, soft coral, sponge, turf algae, urchin, rubble and sand). Live corals were further sub-divided into seven distinct growth-forms (branching / corymbose, encrusting, foliose, massive, mushroom, sub-massive / columnar and tabular).

\section{Fish community}

A fish count was conducted at each survey station following the method of Nash et al. (2013), with all non-transient, non-cryptic diurnally-active fish recorded to species level within a $5 \mathrm{~m}$ radius of a single diver, who conducted all survey assessments. Fish were identified sequentially within fish families, starting with the larger more mobile species and ending with the lower mobility families within each observational patch. Standard length of each fish was estimated visually by the observer following in-water training using known object lengths. The same diver surveyed each patch immediately on arrival to the reef and for 10 minutes in total to ensure consistency of survey effort. Each survey patch was a minimum of 15 metres distance from any other surveyed patch to prevent any potential repetitive counts of individuals (Wilson et al., 2007).

Fish biomass was calculated for each (size-grouped) species following the standard Weight Length relationship (Froese, 2006), where $W=a L^{b}$, with the values of constants $a$ and $b$ based on species-specific calculations obtained from FISHBASE (Froese \& Pauly, 2018; Froese, Thorson, \& Reyes, 2014). Biomass was further classed into target and non-target species. Target families include: Acanthuridae, Caesionidae, Haemulidae, Labridae, Lethrinidae, Lutjanidae, Mullidae, Nemipteridae, Pomacanthidae, Scaridae, Serranidae and Siganidae. Diversity metrics were calculated for each species assemblage using the $\mathrm{R}$ package 'vegan' (Oksanen et al., 2017), with resulting richness values rarefied using the rarefy () function.

\section{Fish traits}

Traits linked with each reef-associated fish species were extracted from FISHBASE using the R package 'Rfishbase' (Boettiger, Lang, \& Wainwright, 2012). Fish 'Feeding type' was split into six categories (substrate browsers, aquatic plant grazers, macrofauna predators, parasite cleaner, selective planktivores, and variable feeders). 'Resilience to fishing' was split into 
four categories (High, Medium, Low, Very low), and is based on multiple life-history parameters including, intrinsic population growth rate, von Bertalanffy growth co-efficients, fecundity, age at maturity and longevity, for all matching species. The 'low' and 'very low' categories were pooled due to limited occurrence of the 'very low' resilience fish. For more detail on how each resilience category was defined please refer to (Musick, 1999; Supplementary material)

\section{Baseline reference data}

Baseline data for benthic substrate composition (Pandanon, $\mathrm{n}=6$; Batasan, $\mathrm{n}=6$; Bilangbilangan, $\mathrm{n}=7$ ), and family level fish community composition (Pandanon, $\mathrm{n}=10$; Batasan, $\mathrm{n}$ = 11; Bilang-bilangan, $\mathrm{n}=12$ ) were assessed in 1999 (the year of site designations) for each MPA site. Surveys were conducted at comparable depths of 4-10 metres using in situ visual techniques. Substrate cover metrics were assessed using replicated haphazardly placed $50 \mathrm{~m}$ 'Line Intercept Transects' inside and outside of each MPA. Broad substrate types and coral growth forms were categorized in the same way as the 2016 survey methodology with eight broad substrate classes and seven coral growth sub-categories. Family-level fish abundance data were collected along $\sim 15$ minute $(50 \times 5 \mathrm{~m})$ belt transects, with fish sampling locations matched with the benthic substrate surveys. For further survey details please refer to Samoilys et al. (2007).

\section{Statistical Analysis}

Each structural metric and transect-pooled measure of fish biomass, size (standard length) and diversity were compared for differences among sites and between management type (inside or outside of MPA) using two-way crossed ANOVAs (with MPA management type as a two-level fixed factor, i.e. protected and unprotected, and sites as a three-level fixed factor (Control site excluded). Post-hoc Tukey's HSD tests were applied, following tests for normality and homogeneity of variance (using Shapiro-Wilk and Levene's tests respectively). Reef 3D Kurtosis and fish biomass were both log transformed for normality before analysis.

Permutational multivariate analysis of variance (PERMANOVA) was performed over 9999 permutations on a square root-transformed Bray-Curtis dissimilarity matrix (with an added dummy variable to account for zero values) using the $\mathrm{R}$ 'vegan' package functions adonis() and vegdist() (Oksanen et al., 2017), to assess for differences in community composition between sites and MPA treatments, respectively (M. J. Anderson \& Walsh, 2013; Clarke, Somerfield, \& Chapman, 2006). This mild transformation was chosen in order to downweight highly abundant dominant species, and reduce noise, allowing community differences amongst both rare and common species to be detected (Clarke, Chapman, Somerfield, \& Needham, 2006). A similarity percentage analysis (SIMPER) was also applied in vegan to identify species contributing the most to the level of dissimilarity between locations.

Distance-based Redundancy analysis (Legendre \& Andersson, 1999) was applied to the fish Bray-Curtis dissimilarity matrix, using the capscale () function within the R 'vegan' package, to investigate any associations between site fish community assemblages and structural or substrate variables. PERMutational ANOVA tests for significance were based on best-fit environmental data with management factor (whether Inside / Outside MPA) partialled out to test the underlying association between fish and benthos. 
Linear regressions between reef rugosity and fish richness, abundance, diversity and evenness were conducted using the $\mathrm{R}$ function $\mathrm{Im}$ (), and subsequently tested for differences in 2016 inside and outside of protection (two level factor) using ANCOVA. Differences in baseline live coral cover and fish abundance inside and outside of the MPAs and at a control site were tested using two-way ANOVA, without an interaction effect due to unbalanced sample sizes. Fish data was square-root transformed to meet the assumptions of normality. ANCOVA was used to investigate the interacting effect of protection on live coral through time. No tests were applied to test changes in fish communities through time due to non-comparable sampling strategies.

All analyses were carried out using R: version 3.4.1 (R Core Team, 2016).

\section{Results}

\section{Benthos}

\section{$\underline{\text { Baseline coral cover (1999) }}$}

Two-way crossed ANOVA showed no significant difference in coral cover inside MPAs compared to outside for any site $\left(\mathrm{F}_{1,15}=0.126, \mathrm{p}=0.728\right)$, but a significant difference in cover was seen between sites $\left(\mathrm{F}_{2,15}=12.279, \mathrm{p}<0.001\right)$ due to significantly decreased cover in Pandanon $(\mathrm{p}<0.001)$ relative to Bilang-bilangan, following Tukey post-hoc tests.

\section{$\underline{\text { Benthic broad substrate cover }}$}

Reefs within the Bilang-bilangan MPA (low impact area) have the highest mean live coral cover of all sites at $80 \% \pm 6(\mathrm{SE})$, and cover is predominantly composed of structurally complex branching or corymbose growth forms $(58 \% \pm 9)$, massive growth forms $(16 \% \pm$ 3 ), and very little rubble $(9 \% \pm 4)$ (Figure 3). Live coral cover is significantly lower on reef outside of protection at $53 \% \pm 3$ (SE), and is largely a monocrop of stands of branching Acropora spp. (51\% $\%$ ), much of which is damaged, leading to relatively high levels of rubble $(43 \% \pm 4)$. 


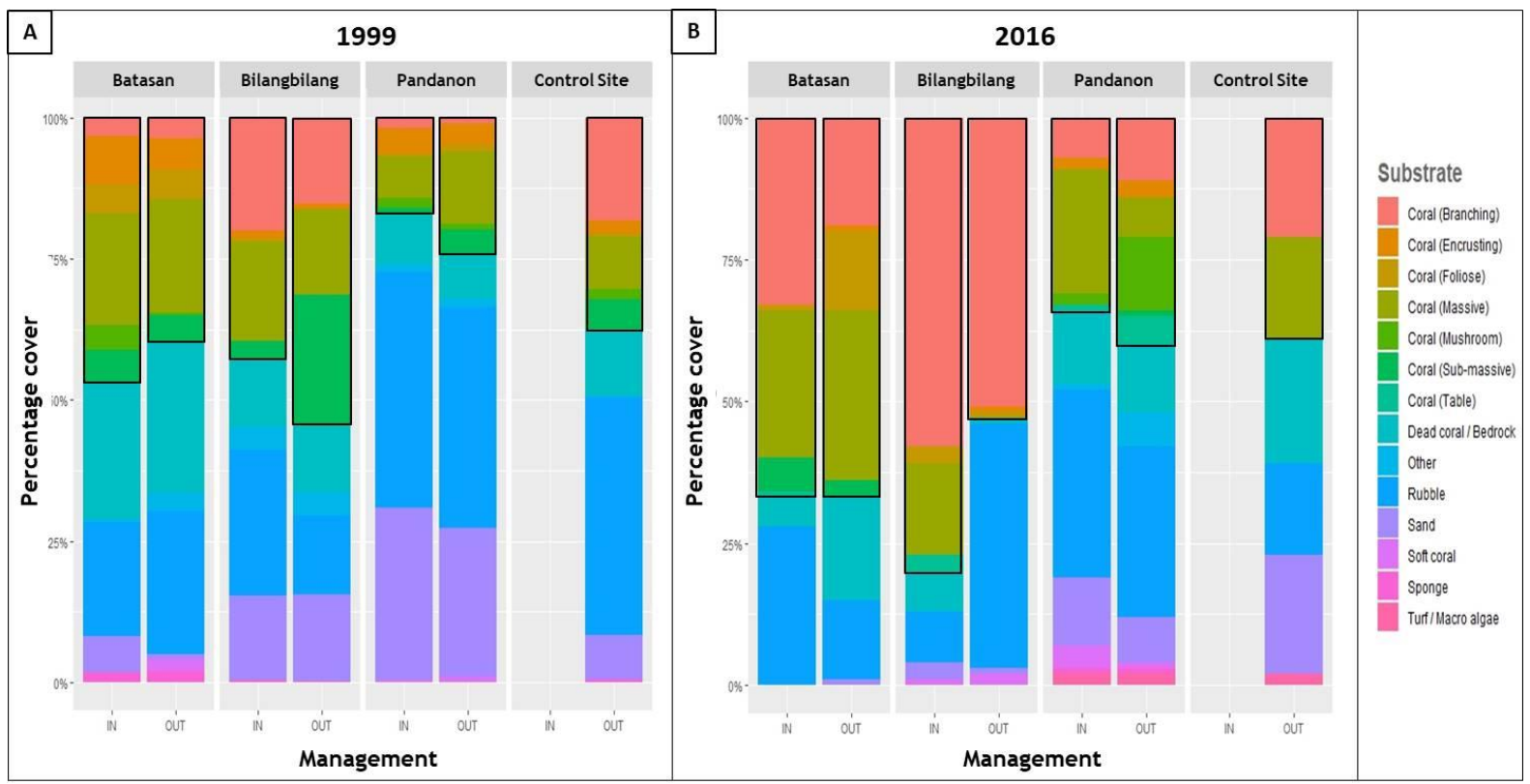

Figure 3. Average percentage cover of broad substrate classes found inside and outside of MPAs within the Danajon Bank, Philippines during A) 1999 and B) 2016. Live coral is highlighted with a black border line and is further split into 7 major coral growth forms.

High overall live coral cover is seen within the Batasan MPA (moderate impact area), with a mean of $67 \% \pm 10(\mathrm{SE})$, primarily composed of branching / corymbose $(33 \% \pm 10)$ and massive growth forms $(26 \% \pm 7)$. There is, however, high variation among samples, due to damage of the dominant branching forms, with rubble coverage reaching $28 \% \pm 8$. Although overall live coral cover outside the MPA is also $67 \% \pm 6$ (SE), mean dead coral cover is three times higher at $18 \% \pm 4$, with high rubble $14 \% \pm 2$. Overall live cover is largely driven by mono-crops of fast-growing and structurally complex foliose Montipora spp. $14 \% \pm 10$ and branching Acropora spp. $19 \% \pm 6$, similar to the situation observed around Bilang-bilangan.

The lowest overall live coral cover is seen in the Pandanon MPA (high impact area), with a mean of $34 \% \pm 8$ (SE), primarily composed of massive colonies $22 \% \pm 8$ with the remaining substrate dominated by fine loose rubble $33 \% \pm 10$ as well as dead standing coral $13 \% \pm 5$ and gravelly sand $12 \% \pm 8$. This area is also the only site with turf macro-algae observed (2\% \pm 4 both inside and outside of the MPA) and Diadema urchin presence $(1 \% \pm 1$ and $6 \% \pm 3$ inside and outside of the MPA respectively). Outside of the MPA live coral is at $40 \% \pm 6$, composed of vaired mix of growth forms, but dominated by mushrooms $(13 \% \pm 7)$, branching $(11 \% \pm 3)$, and massive $(7 \% \pm 3)$ forms.

Although cover of live coral is higher outside of the Pandanon MPA, this difference is driven largely by the inundation of high densities of free-living Fungia in a number of samples, living on top of underlying highly mobile rubble. The mushroom coral aggregations were of mixed species from the family Fungiidae and were observed in multiple locations at peak densities of $\sim 250$ individuals $\mathrm{m}^{-2}$, compared to average surrounding densities of $1-4$ individuals $\mathrm{m}^{-2}$. The communities consisted primarily of species from the genera Fungia, Herpolitha and Ctenactis living on top of a mobile coral rubble matrix. When this is accounted for, hermatypic live coral cover falls from $40 \%$ to $27 \%$ outside of protection.

Comparable ratios of substrate cover are seen in the control site of Canlangi to Pandanon, with low overall coral cover of $39 \% \pm 4(\mathrm{SE})$, with only massive and branching growth 
forms, and high quantities of rubble $(16 \% \pm 5)$, coarse sand $(21 \% \pm 7)$, dead coral $(22 \% \pm 4)$, and turf algae $(2 \% \pm 2)$ (Supplementary material).

ANCOVA found level of MPA protection to be a significant predictor for percentage cover of live coral over time in the sampled sites $\left(\mathrm{F}_{5,42}=3.282, \mathrm{p}=0.0137\right.$, Adj $\left.\mathrm{R}^{2}=0.195\right)$. Protected sites saw the only significant slopes through time $(\mathrm{t}=3.166, \mathrm{p}=0.0029)$, with average cover increasing by $1.75 \% \pm 0.55$ per year over the sample period, and with no significant effects observed for sites outside of protection or at the control site.

\section{Benthic 3D physical structure}

Two-way crossed ANOVA showed significantly different reef 3D rugosity ratios between sites $\left(\mathrm{F}_{2,24}=44.507, \mathrm{p}<0.001\right.$; Figure 4$)$, due to lower rugosity in Pandanon $\left(\mathrm{p}_{\mathrm{adj}}<0.001\right)$. There was no overall significant difference in reefs inside MPAs compared to outside $\left(\mathrm{F}_{1,24}=\right.$ 2.502, $\mathrm{p}=0.127)$, however, there was an interaction effect $\left(\mathrm{F}_{2,24}=4.071, \mathrm{p}=0.030\right)$, due to lower rugosity inside Batasan MPA compared to outside $\left(\mathrm{p}_{\text {adj }}=0.036\right)$.
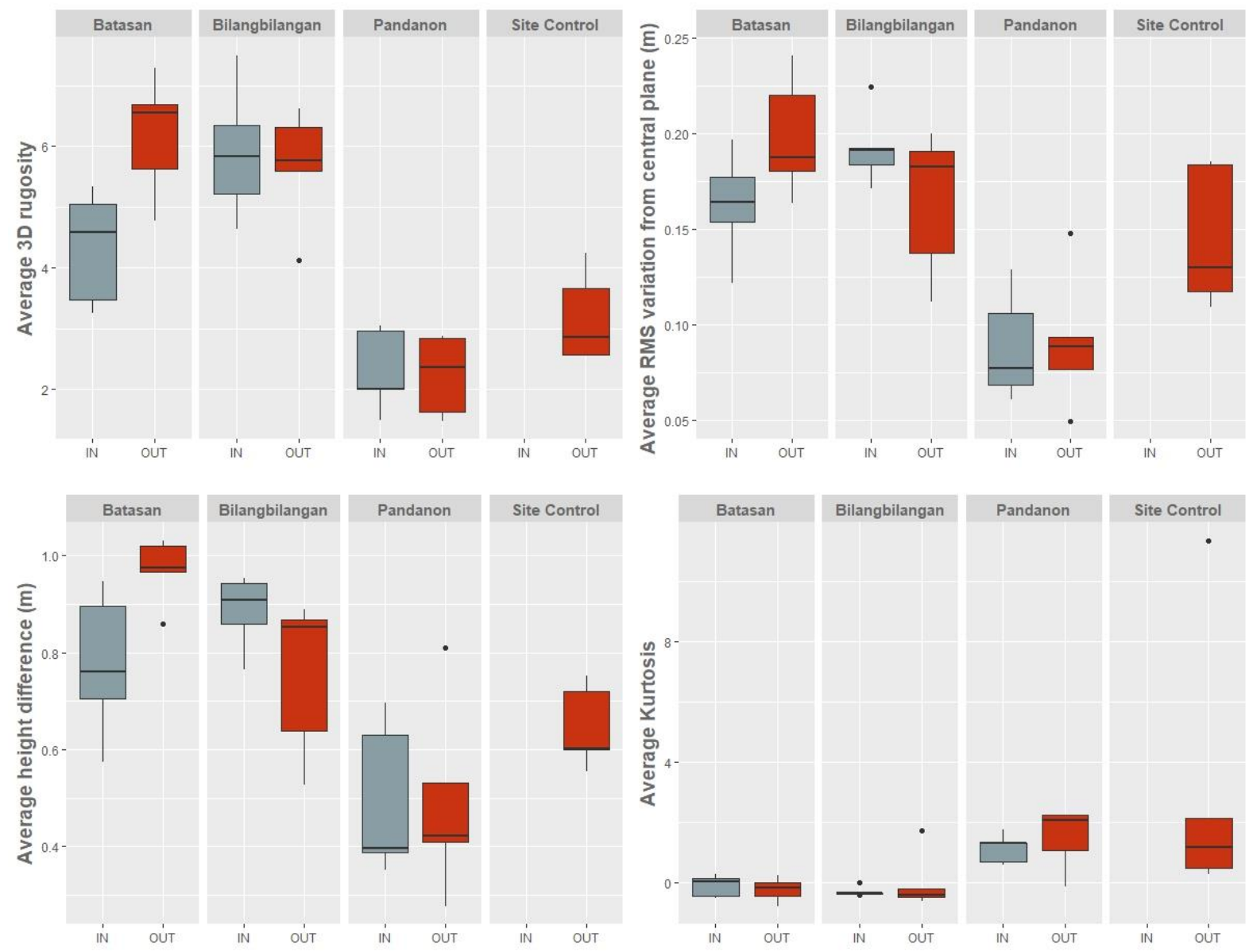

Figure 4. Boxplots of 3D structural metrics (rugosity, RMS point variation, surface kurtosis, and surface height difference) of reefs found inside and outside of MPAs within the Danajon Bank, Philippines. Values for each metric were obtained from averaging across nine subsamples for each site replicate. Boxplots illustrate the median values, inter-quartile range (filled boxes) and outlier values for each site. 
Reef height (max-min) variation was significantly different between sites $\left(\mathrm{F}_{2,24}=20.712, \mathrm{p}\right.$ $<0.001$ ) due to lower reef height in Pandanon ( $\mathrm{p}_{\text {adj }}<0.001$ ). There was no overall significant difference in reefs inside MPAs compared to outside $\left(\mathrm{F}_{1,24}=0.146, \mathrm{p}=0.705\right)$, however, there was a marginal interaction effect $\left(\mathrm{F}_{2,24}=3.216, \mathrm{p}=0.058\right)$, due to lower height inside Batasan MPA compared to outside ( $\left.\mathrm{p}_{\text {adj }}=0.047\right)$.

Reef 'spikiness' / roughness (RMS variation from a central plane) was significantly different between sites $\left(F_{2,24}=28.366, p<0.001\right)$ due to flatter reefs in Pandanon $\left(\mathrm{p}_{\mathrm{adj}}<0.001\right)$. There was no overall significant difference in reef spikiness inside MPAs compared to outside $\left(\mathrm{F}_{1,24}\right.$ $=0.101, \mathrm{p}=0.753)$, however, there was a marginal interaction effect $\left(\mathrm{F}_{2,24}=2,699, \mathrm{p}=0.088\right)$, due to flatter reef inside Batasan MPA compared to outside $\left(\mathrm{p}_{\mathrm{adj}}=0.024\right)$.

Reef kurtosis (sharpness/ spikiness of the surface) was significantly different between sites $\left(F_{2,24}=13.433, p=0.002\right)$ due to sharper peaks in Pandanon relative to Batasan $\left(p_{\text {adj }}=0.002\right)$ and Bilang-bilangan relative to Batasan $\left(\mathrm{p}_{\mathrm{adj}}=0.037\right)$. There was no overall significant difference in reef kurtosis inside MPAs compared to outside $\left(\mathrm{F}_{1,24}=2.010, \mathrm{p}=0.190\right)$, or any significant interaction effect $\left(\mathrm{F}_{2,24}=0.256, \mathrm{p}=0.625\right)$.

\section{Fish community metrics}

Baseline fisheries data (1999)

Two-way crossed ANOVA showed no significant difference in fish abundance inside MPAs compared to outside $\left(\mathrm{F}_{1,29}=0.322, \mathrm{p}=0.575\right)$, but a significant difference in abundance was seen between sites $\left(\mathrm{F}_{2,29}=6.689, \mathrm{p}=0.004\right)$ due to significantly increased abundance in Bilang-bilangan relative to Batasan $(\mathrm{p}=0.005)$ and to Pandanon $(\mathrm{p}=0.046)$ following Tukey post-hoc tests.

\section{$\underline{\text { Present fisheries data (2016) }}$}

Two-way crossed ANOVA showed significantly higher Shannon-Weiner diversity of fish species inside MPAs than outside $\left(\mathrm{F}_{1,24}=37.37, \mathrm{p}<0.001\right.$; Figure 5), but there was no significant difference in diversity between sites $\left(\mathrm{F}_{2,24}=0.996, \mathrm{p}=0.384\right)$, and no interaction effect $\left(\mathrm{F}_{2,24}=0.681, \mathrm{p}=0.516\right)$. There was significantly higher fish size inside MPAs than outside $\left(\mathrm{F}_{1,24}=21.862, \mathrm{p}<0.001\right)$, and significant differences between sites $\left(\mathrm{F}_{2,24}=5.368, \mathrm{p}=\right.$ $0.012)$, caused by marginally greater fish size in Pandanon relative to Batasan $\left(\mathrm{p}_{\mathrm{adj}}=0.086\right)$, and no interaction effect $\left(\mathrm{F}_{2,24}=0.669, \mathrm{p}=0.521\right)$. 


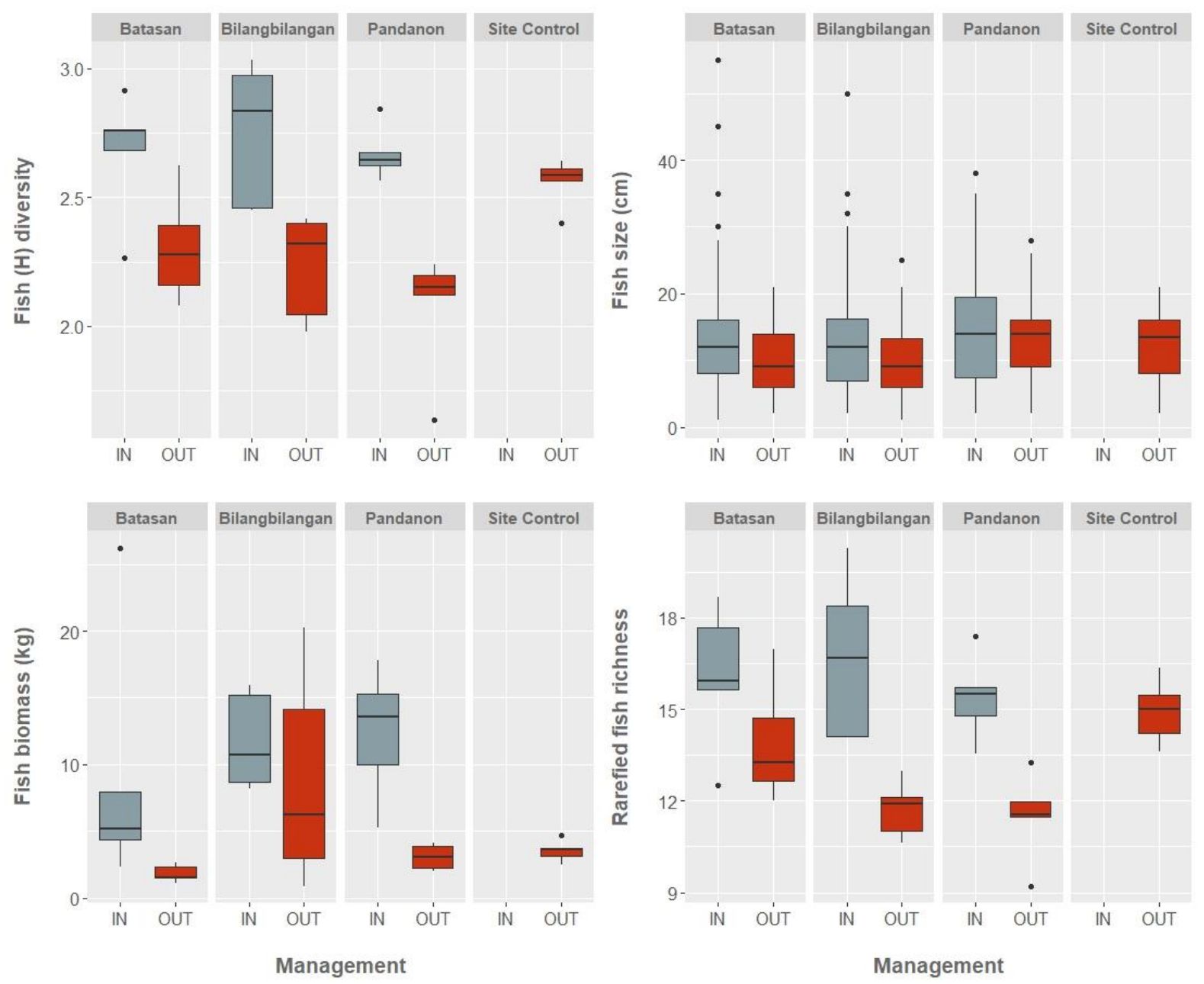

Figure 5. Boxplots of fish Shannon-Weiner diversity index, size (standard body length), biomass $(\mathrm{kg})$, and rarefied richness, split between locations inside and outside of management within the Danajon Bank. Boxplots illustrate the median value, inter-quartile range (filled boxes) and outlier values for each site. Control site also shown.

There was significantly higher fish biomass density inside MPAs than outside $\left(\mathrm{F}_{1,24}=19.905\right.$, $\mathrm{p}<0.001$ ). Total biomass density inside $=424.48$ tonnes $\mathrm{km}^{-2}$ (of which target species $=$ 295.63 tonnes $\mathrm{km}^{-2}$ ), while total biomass density outside $=174.87$ tonnes $\mathrm{km}^{-2}$ (of which target species $=114.98$ tonnes $\mathrm{km}^{-2}$ ). There were furthermore significant differences between sites $\left(\mathrm{F}_{2,24}=3.834, \mathrm{p}=0.036\right)$, caused by the lower biomass in Batasan relative to Bilangbilangan ( $\left.\mathrm{p}_{\mathrm{adj}}<0.001\right)$, but no interaction effect $\left(\mathrm{F}_{2,24}=0.634, \mathrm{p}=0.539\right)$. There was significantly higher rarefied fish richness inside MPAs than outside $\left(F_{1,24}=28.082, p<0.001\right)$, but there was no significant difference in richness between sites $\left(F_{2,24}=1.693, p=0.205\right)$, and no interaction effect $\left(\mathrm{F}_{2,24}=1.397, \mathrm{p}=0.267\right)$. Finally, there were no differences in evenness at a management level $\left(\mathrm{F}_{1,24}=2.546, \mathrm{p}=0.124\right)$, site level $\left(\mathrm{F}_{2,24}=0.687, \mathrm{p}=0.513\right)$, or through interaction effects $\left(\mathrm{F}_{2,24}=0.959, \mathrm{p}=0.398\right)$.

PERMANOVA showed fish communities to be significantly different between sites (pseudo$\mathrm{F}_{3,28}=6.193, \mathrm{p}=0.001$ ), and between management type (pseudo- $\mathrm{F}_{3,28}=3.326, \mathrm{p}=0.001$ ), explaining $32.9 \%$ and $17.6 \%$ of community dissimilarity respectively. Dendrogram cluster analysis further showed that Batasan and Bilang-bilangan (both inside and outside of protection) were clustered (at the $3^{\text {rd }}$ branch level), as was Pandanon (outside of the MPA) 
with the unprotected control site, and with a final distinct community inside the Pandanon MPA (Figure 6). At the $5^{\text {th }}$ branching level of clusters, Pandanon (inside), the site control, and Bilang-bilangan all further separate to form additional distinct cluster groups.

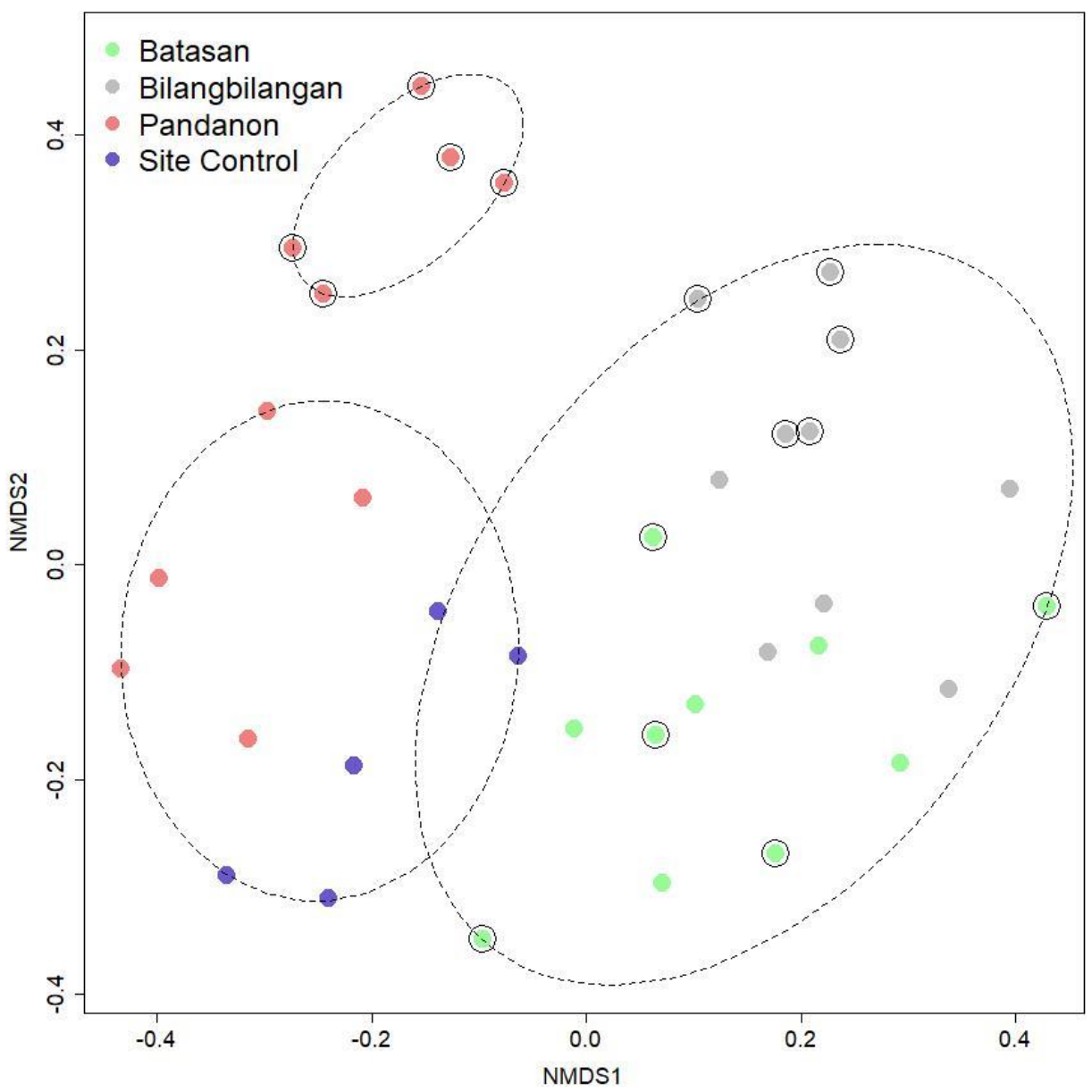

Figure 6. NMDS plot of fish community dissimilarities within the Danajon Bank, Philippines, with site and management type as factors. Sites inside MPA management illustrated with black circles, 3rd group level similarity cluster convex hulls shown with dashed line. 2D Stress $=0.20$

SIMPER analysis showed that over half of the dissimilarity between protected and unprotected sites related to differences in relative abundances of species from the Pomacentridae family, with species from Scaridae and Labridae representing the next most important families for driving community differences (Figure 7). On a site level, the outside of Pandanon saw the most notable loss in family diversity, with the Acanthuridae and Pomacanthidae, (both common inside the MPA), entirely absent outside, and replaced by proportionally higher abundances of families such as Labridae and Siganidae.

In terms of generalized family-level feeding guilds, there was a reduction of guilds outside of the MPAs from six to four types, (losing substrate browsers and parasite cleaners), and showing reductions in macrofauna predators, plant grazers and planktivores (Figure 7). Communities outside of MPAs only had species which are classed as medium-highly resilient, i.e. fish with high fecundity / rapid growth etc. (Froese \& Pauly, 2018), whereas 
communities inside of MPAs contained high-very low resilience fish species. Low/very low resilience species at this location included: Ctenochaetus striatus, Naso unicornis, Scarus altipinnis, Coris aygula, Plectorhinchus chaetodonoides, and Cheilinus undulatus, which all have a minimum population doubling time of 4.5 - 14 years (Froese \& Pauly, 2018). These slow-growing species, which are particularly vulnerable to over-extraction, were found to only occur inside MPAs (Figure 7). 


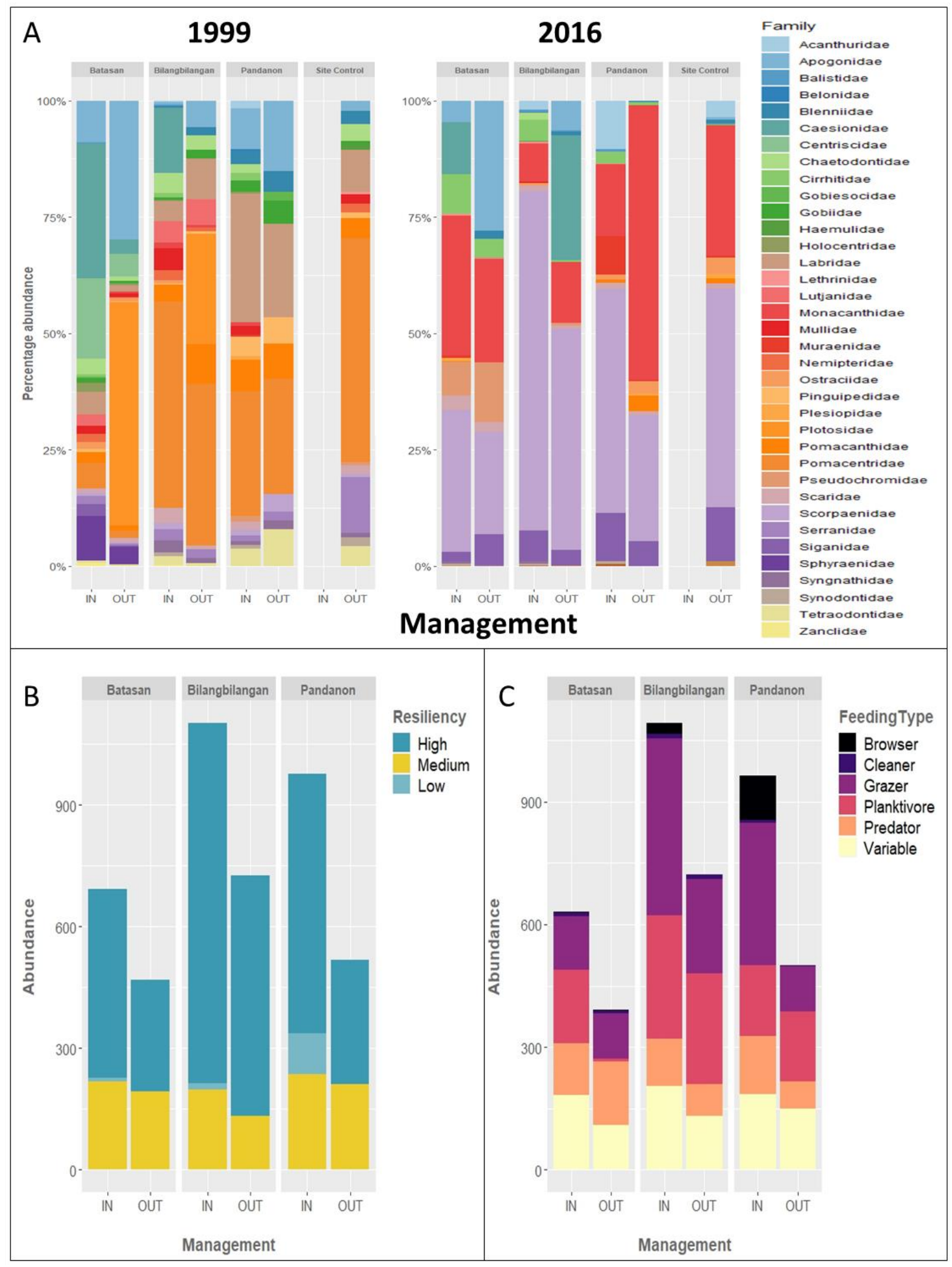

Figure 7. Relative percentage abundances of: A) fish families during 1999 and 2016; B) 2016 fish resilience, and; C) 2016 feeding guilds at each of the three sites along the Danajon Bank, inside and outside of MPA management. 


\section{Fish-reef associations}

Distance-based redundancy analyses were conducted to investigate the associations between fish community assemblages (based on Bray-Curtis dissimilarity) and the benthos. Analyses were split into A) fish assemblages against benthic 3D structure metrics, and B) fish assemblages against cover of broad reef substrate class, with the effect of the MPA management variable removed (partialled out) from the analysis.

The 3D structural complexity metrics (rugosity ratio, kurtosis, skew, RMS variation and Z height difference) together explained $19.5 \%$ of the fish variation between sites (Figure 8), however, rugosity ratio was the only significant structural metric (Capscale permutation tests: $\mathrm{p}=0.005$ ), explaining $10.1 \%$ of the fish assemblage variation. Bilang-bilangan's reef fish assemblage is structured by relatively higher rugosity, increased relative height and greater surface roughness, whereas Pandanon and Canlangi's reef fish assemblages are structured by higher kurtosis and skew, but strongly reduced rugosity and roughness. 

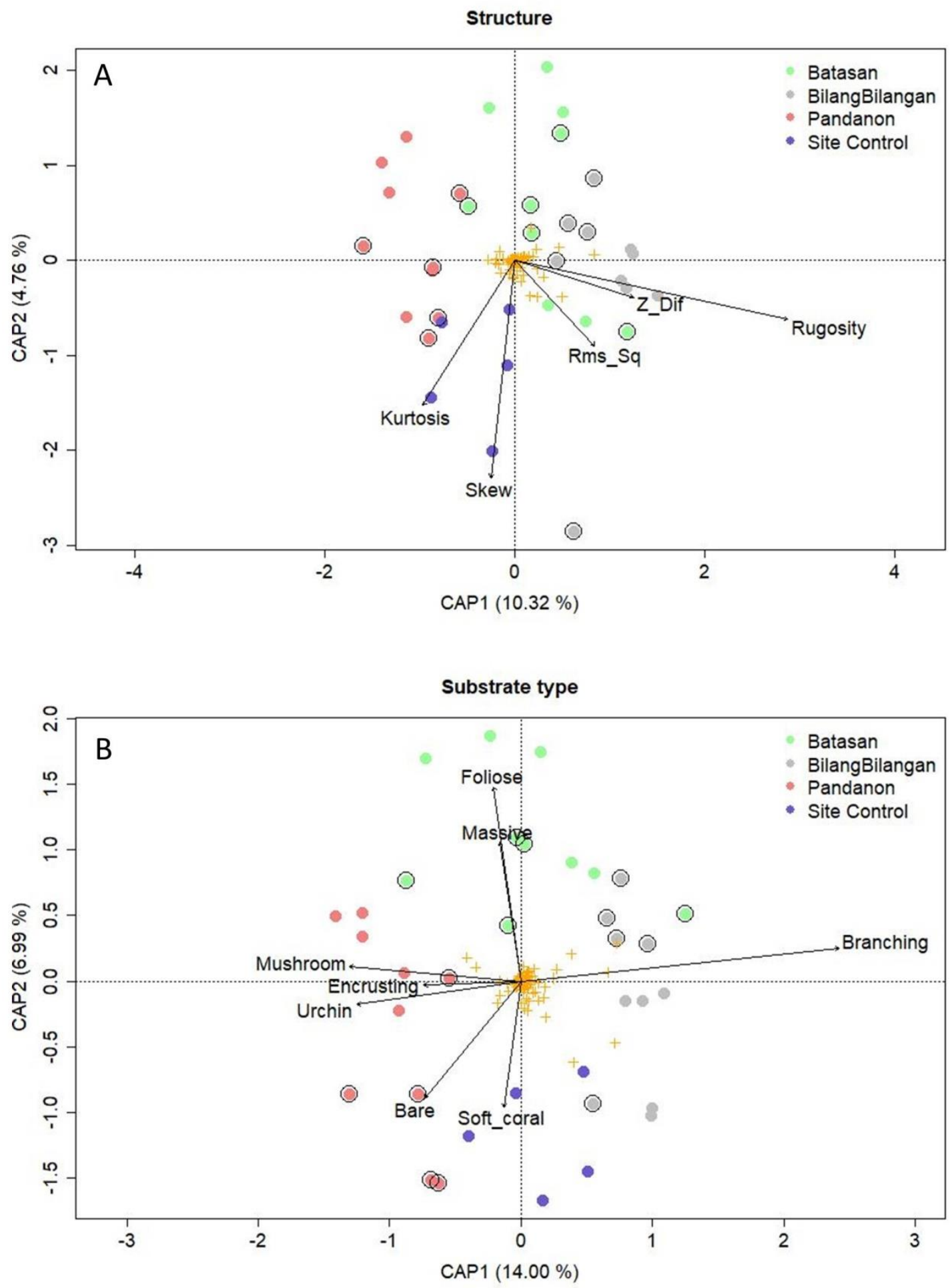

Figure 8. Distance-based redundancy analysis of fish community structure relative to A) benthic structural metrics ('Rms_Sq' = Root Mean Square surface roughness; 'Z_Dif' = Height difference) and B) broad substrate type and coral growth forms for all sites. Relative positioning of coloured circles shows levels of community similarity for each site, with arrows showing direction and strength of each abiotic factor in explaining fish community structure. Orange crosses symbolise species' importance, and the sites within MPA protection are illustrated with black outer rings. 
Benthic substrate types and coral growth form sub-categories collectively explained $38.4 \%$ of fish variation (Figure 8). Branching coral, table coral and bare/dead coral were the only substrate types causing significant variation in fish communities (Capscale permutation tests: $\mathrm{p}=0.005, \mathrm{p}=0.025$ and $\mathrm{p}=0.015$, respectively), together explaining $21.2 \%$ of the fish variation. Bilang-bilangan and Batasan's fish assemblages are structured by benthos with higher levels of branching, foliose and massive corals, whereas Pandanon's fish assemblages are structured by higher levels of encrusting, mushroom and table corals, and greater turf and urchin abundance. Canlangi's fish assemblages are structured by substrates with higher soft coral cover.

Linear regression showed a significant positive relationship between $3 \mathrm{D}$ rugosity ratio and fish richness $\left(\mathrm{F}_{1,13}=5.96, \mathrm{p}=0.030\right)$ for areas sampled inside MPAs, with rugosity explaining $31.4 \%$ of the variation in fish richness (Figure 9). However, rugosity was not significantly related to fish richness for samples outside of MPAs $\left(F_{1,13}=0.61, p=0.449\right)$, and explained only $4.5 \%$ of the variance. A similar pattern emerged for the relationship between rugosity and abundance, which was significant inside $\left(\mathrm{F}_{1,13}=3.62, \mathrm{p}=0.079\right)$, but not outside of MPAs $\left(\mathrm{F}_{1,13}=1.59, \mathrm{p}=0.230\right)$, and rugosity explained $21.8 \%$ of the variation in fish abundance inside MPAs. Values of fish richness, abundance and diversity were all typically higher inside MPAs.
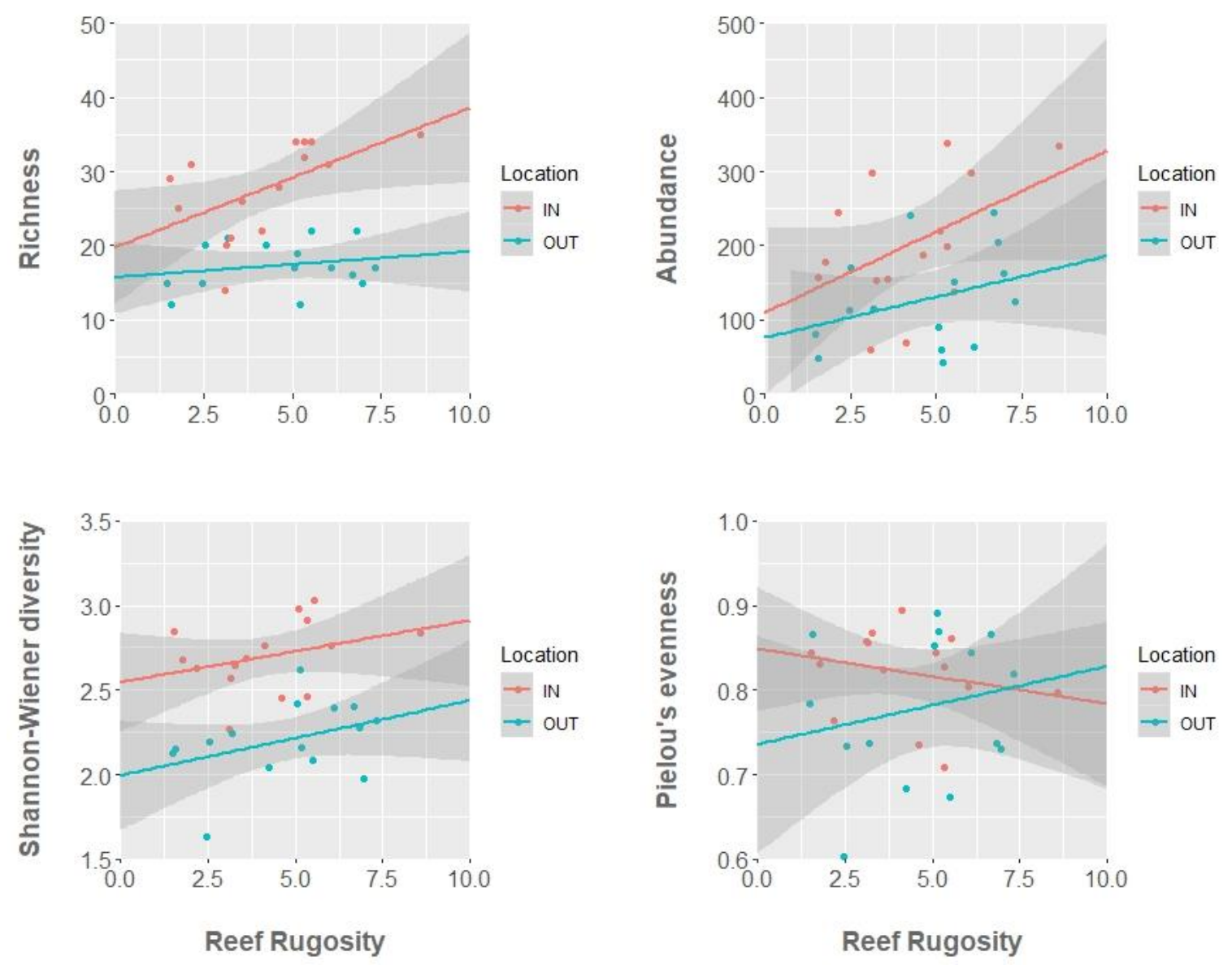

Figure 9. linear models of the relationship between rugosity and fish richness, abundance, diversity (Shannon-Weiner), and evennes, inside and outside of 3 MPAs in the Danajon bank, Philippines. Standard error confidence boundaries shown. 
There was no significant relationship inside or outside of MPAs between rugosity and Shannon-Weiner diversity $\left(\mathrm{F}_{1,13}=1.53, \mathrm{p}=0.239 ; \mathrm{F}_{1,13}=2.25, \mathrm{p}=0.158\right)$, Simpson's Index $\left(\mathrm{F}_{1,13}=0.43, \mathrm{p}=0.525 ; \mathrm{F}_{1,13}=0.95, \mathrm{p}=0.348\right)$ or evenness $\left(\mathrm{F}_{1,13}=0.78, \mathrm{p}=0.393 ; \mathrm{F}_{1,13}=\right.$ $0.61, p=0.449)$. Analysis of Covariance showed significant variation inside and outside of MPAs in the relationship between rugosity and fish richness $\left(\mathrm{F}_{1,27}=40.79, \mathrm{p}<0.001\right)$, Shannon-Weiner diversity $\left(\mathrm{F}_{1,27}=44.87, \mathrm{p}<0.001\right)$, and abundance $\left(\mathrm{F}_{1,27}=9.44, \mathrm{p}=\right.$ $0.0048)$, but not evenness $\left(\mathrm{F}_{1,27}=2.59, \mathrm{p}=0.119\right)$.

\section{Discussion}

This study found higher biomass, richness, diversity and size of fish inside protected areas compared with outside, despite their relatively small size (16-34 ha), consistent with other studies, both globally and in this region (da Silva, Hill, Shimadzu, Soares, \& Dornelas, 2015; Edgar et al., 2014; Russ, Miller, Rizzari, \& Alcala, 2015; Turnbull et al., 2018). In broad terms the long-term management of the three small scale study sites is therefore seen to be working for fish communities. The effect of protection was most markedly seen in Batasan with roughly four times greater total biomass inside the MPA than outside. Alongside the greater fish diversity and biomass in managed areas, fish community composition was also significantly different, with highly reef-dependent fish families such as the damselfish (pomacentridae) being lost from areas where structure was reduced. The key drivers of these differences in community assemblages were seen to be the MPA management, level of reef rugosity, and the relative proportion of coral growth forms.

The presence of high structural complexity is an essential metric for predicting the recovery outcome of a disturbed reef system, and influences the diversity and productivity of associated organisms (Graham et al., 2015). In this study we found structural complexity explains a significant amount of the variation in fish community structure and is positively correlated to fish abundance and richness (most strongly within protected reef sites). Historic methods of structural complexity assessment which typically record only a single dimensionless aspect of the reef's morphology (with low accuracy, precision and repeatability) therefore need to be improved upon if we are to fully capture important structural changes.

The 'Structure from Motion' photogrammetric method applied within this case study was found to be a useful technique for the rapid quantification of multiple aspects of structure, and for producing large-scale ortho-rectified HD images of the reef. Both such outputs are very valuable for detailed monitoring and assessment of a reef's status, and help to give consistency and transparency to monitoring programmes, since data can directly compared and re-analysed ex-situ. The range of morphometric outputs which one is able to relatively simply extract from the technique enables researchers to improve their ability to quantitatively describe the physical characteristics of a reef environment through time. These metrics are also produced in an archivable format, allowing for greater insight (either now or retrospectively) into the state of the reefs, the reasons for any changes which have occurred, and the appropriate management measures from which they may benefit. SfM is furthermore non-destructive, and aside from the cost of the underwater camera and a medium performance computer, is in most parts free to use, i.e. relatively affordable in terms of software use, even for low-budget monitoring programmes (Bayley et al., 2019).

There are however important limitations to the application of this technique for appropriate monitoring and assessment. Firstly it is necessary to have relatively clear water, appropriate 
lighting and preferably slack / still waters in order to produce models which are clear and have full coverage. In the case of strong swell or currents it can be physically exhausting for the diver to image large areas, and such conditions can cause excessive motion of semimobile substrate (for example soft corals or algae) making it extremely difficult to create useful models over a large area with this technique. Similarly, highly turbid waters become difficult to adequately image as the distance from the reef to the lens has to be reduced (and therefore image number must increase to allow sufficient image overlap), losing light to the lens and resulting in overly dark / flat / blurred images which typically create low-quality models (Ferrari et al., 2016; Raoult et al., 2016). Linked with all these factors is the need for a good basic understanding of underwater photography, as while action cameras such as GoPros are affordable and easy to operate, the 'SLR' or even 'compact' style cameras (which will typically produce higher resolution results), are initially harder to master. This initial learning curve may potentially be a limiting factor in the uptake of this method if appropriate training is not available.

A further consideration is the site topography itself, with the technique best suited to level reef flats and light slopes, with low to moderate surface relief. As the slope incline increases to a $90^{\circ}$ wall or overhang, the technique (while still possible) becomes logistically more difficult at large scales $(>10 \mathrm{~m})$ using diver-operated systems. This is due to the multiple successive changes in depth needed over a steep slope in order to produce a zig-zagged 'lawn-mower' overlapping grid pattern. Reefs which are extremely complex, containing dense branching coral thickets, highly overlapping table corals, or multiple tall bommies etc., are also problematic, often causing the model to produce multiple areas of 'occlusion'. Occlusion occurs when aspects of the reef scene are obscured and it becomes impracticable to image the surface adequately, resulting in empty / un-modelled sections of the 3D model. This can lead to over-estimation of volume from interpolated occluded sections of the reef surface, particularly with table growth forms, or underestimation of complexity / roughness with branching/corymbose growth forms (Bayley et al., 2019; Lavy et al., 2015; Raoult et al., 2017).

A final technical consideration is the quality of the camera itself and the resolution of the images which are used to create the model. Digital resolution is the most basic limitation to the detail and accuracy with which models can be created. However, the benefits of using higher resolution imagery need to be balanced with the corresponding increases in processing time and computing requirements to create a model. Coupled with these considerations is the need to think carefully about the scale and fractal dimension at which any post-processing surface structure analysis is conducted, as this will strongly affect the outputs.

\section{Barriers to the use of SfM}

There is clearly still further research needed on how each of the previously described factors affects the accuracy and comparability of model outputs, in order to reassure users of the consistency and comparability of new measurements to historic survey data (Bayley et al., 2019) Ultimately however, the choice of whether to employ this method will depend on the nature of the reef assessment work which is being carried out. Visual methods are rapid, cheap and require minimal training, but are limited in their outputs and lack quantitative detail, whereas acoustic methods such as multibeam echosounding can cover large areas, but can be prohibitively expensive, are difficult to operate, and lack fine-scale detail (Bayley \& Mogg, 2019). SfM is therefore perhaps best suited for small or medium-scale reef sites where there is a need to improve fine-detail quantitative reef structure data (greater than a basic 
visual assessment), particularly for lower-income countries due to the relatively low costs (Bayley et al., 2019). But despite this technique being relatively straightforward to instigate, for any new technology to be successfully adopted and usefully applied by local managers with limited resources, some initial training in survey technique, processing and model analysis would be required, along with standardised protocols of how to apply this method over various habitat types and scales (Bergman et al., 2009; Carboni et al., 2016).

The barriers which are most likely to hamper the uptake of this method are: 1) the initial additional cost involved in purchasing camera and computing equipment of sufficient quality to create good models if not already available; 2 ) the processing time and computing power needed for creating very large detailed models; and 3) a need for skills training in this new monitoring method. Nevertheless, the rapid development of computing hardware and software are likely to result in the first two points soon becoming far less important obstacles, with high specification cameras such as the GoPro now available for a few hundred pounds and requiring limited training. Furthermore, one of the benefits of the SfM technology is that it only requires a normal underwater camera and a high power computer (both of which are typically a standard part of a survey teams' toolkit anyway). Therefore, aside from the new software needed, these limitations may not infer a too heavy additional cost for lower income projects / regions. Linked with this is the increasing accessibility of the internet and development of 5G mobile technology which will likely allow even relatively remote locations to soon be able to upload data to cloud-based / cluster processors. Cloud-based technology will minimize the processing time necessary locally, and allow larger areas of reef to be surveyed through increased memory and processing capacity.

Once such computing power has developed sufficiently to allow processing times to be reduced, (and the technique has become more established, reducing the likely initial resistance to using new techniques), the methodology can be begin to be scaled across areas of far greater size. The current restriction to medium-scale discrete patches of reefs (such as the $\sim 100 \mathrm{~m}^{2}$ reef areas at which this study has worked), means that we are potentially missing changes occurring elsewhere on the reef, or changes which are occurring over larger spatial scales (Aston et al., 2019). If we are able to increase the spatial coverage of data recorded at high resolution, likely through the use of Autonomous Underwater Vehicles and Unmanned Aerial Vehicles (drones), we may be able to start seeing such ecological patterns and changes. This will in turn hopefully allow deeper insights into coral reef ecology (including how associated organisms such as sharks use this space), while also allowing more effective management monitoring to be conducted (Fukunaga, Burns, Craig, \& Kosaki, 2019; Lea, Humphries, von Brandis, Clarke, \& Sims, 2016).

\section{Ecological effects of management}

The reduction in the number and range of families and feeding guilds we observed outside of the MPAs would appear to be driven by fishing exploitation, but given that many of the fish species are not typically directly exploited for food, these differences could also potentially be driven by the loss of a range of invertebrate food sources which normally live in healthy reef structures (Pratchett, Hoey, Wilson, Messmer, \& Graham, 2011). The loss of live coral as a food source for obligate corallivores in the heavily blast-damaged sites could also potentially be driving the associated declines in fish abundance and diversity. These differences in fish community assemblage structures have led to three broad groups appearing: firstly the Batasan and Bilang-bilangan sites show a great deal of overlap in communities, even outside of protection; then the communities of the control site and 
Pandanon (outside of protection) are shown to be grouping together; and finally a transitional group in the protected Pandanon area, somewhere in-between the two is shown. Alongside the changes in abundance it is also apparent that the composition of fish species has shifted for all sites since their creation 17 years ago. Despite having baseline data for these sites, it is important to be careful interpreting or extrapolating the observed effects of these reserves since natural (non-management) site effects on abundance and community structure may be confounding the recovery outcomes (Osenberg, Shima, Miller, \& Stier, 2011). This is especially important given the relatively low number of sites included in this case study.

The greatest differences between benthic communities were seen between sites, rather than relating to the reef's position inside or outside of an MPA. The structural differences between sites appear to have been caused by the heavy blasting around the Pandanon site, where reefs were an average of 3 times less rugose, and had on average half the height of other reefs (with some samples outside the MPA, reduced to solely fine loose rubble and a rugosity value close to 1). Our observations fit well with other studies, where reefs similar to Pandanon (which have historically experienced widespread extensive blasting), tend to be unable to recover over long periods due to the unconsolidated rubble killing any newly settled coral recruits through current or wave-induced movement (Fox \& Caldwell, 2006; Raymundo, Maypa, Gomez, \& Cadiz, 2007). Furthermore, Fox and Caldwell (2006) showed smaller scale or low frequency damage from blasting caused only localized short-term damage to the reef, with many reefs recovering to comparable pre-damage states within five years. This compares well to the the Bilang-bilangan and Batasan sites here, where blasting has either been discontinued or happens only at low frequency, and no significant differences were seen in structure inside and outside of the MPAs or between the two sites.

The reefs inside the Batasan MPA were observed to be impacted by the local earthquake in 2013, with the physical collapse of many coral stands, a loss of live coral cover, and multiple 1-5 metre fissures forming. The corresponding collapse of the MPA guardhouse is also likely to have led to a reduction of enforcement effectiveness, particularly given that blast fishing activity was known to occur here historically. It should further be noted that increased coral head removal was observed, for use in rebuilding or elevating local island structures following earthquake-induced land subsidence and sea-level rise. Island adaptation to subsidence-induced flooding through elevation of flooring is known to also occur at Bilangbilangan (Jamero et al., 2017), but was not directly observed here.

Across the impacted site of Pandanon, where reefs are now typically flattened rubble fields with very low coral diversity and structure, we observed an unusual proliferation of freeliving mushroom coral species, which now form the dominant component of the reef ecosystem. One previous study (Hoeksema, 2012) suggests that dynamite blasts may in fact cause little damage to free-living mushroom corals, and instead may confer high population densities, due to mushroom coral's ability to regenerate from fragmentation and move freely to re-populate damaged areas and take advantage of the increased light availability. The loss of structural complexity more generally outside of the MPA due to very heavy blast activity, may also be limiting future recruit settlement through the loss of the structure-generated turbulence needed to deliver larvae to the substrate (Hata et al., 2017), and through the loss of sensory cues such as noise, normally generated from healthy reefs (Simpson, 2005). 


\section{Study limitations}

The lack of any statistically significant physical structural differences inside and outside of the MPA boundaries in this study (aside from the earthquake damage in Batasan) was unexpected, and is likely due to two main factors. Firstly, the study is not starting from a pristine baseline scenario for any of the MPAs, and is instead comparing recovery rates from an initially degraded state both inside and outside of MPAs over 17 years. Secondly, we do not have explicit data for level or type of fishing effort at each site. From what is known, much of the fishing pressure in this region is net-, line- or spear-fishing and is therefore typically not directly affecting the substrate. Besides these factors, the significant differences in reef structure between Pandanon and the other sites (within environments which are otherwise comparable) strongly indicates that blast fishing is not only highly destructive, but has consequences for the structure of the reef and fish assemblages which can be discerned even decades following impact.

In addition to the above points, we need to consider an important limitation of the benthic survey method, in regard to the fact that both reef kurtosis and roughness (RMS variation) metrics recorded using SfM will likely follow a bell-shaped distribution as disturbance (such as blasting) increases i.e. at low disturbance we would expect a healthy reef to have a relatively even surface over a coarse scale. However, as holes appear in the reef from blasting damage, the 3D surface layer will be recorded as having higher kurtosis as it becomes more uneven and fractured. Finally, after heavy disturbance such as sustained blasting, the reef will eventually become flattened again as the coral collapses down, resulting in lower kurtosis (toward a zero value) and lower surface variation / roughness. This means that very healthy and very damaged reefs could in theory have similar metrics, so it is essential that for these two metrics (and related measures such as surface skew or fractal dimension), that 3D measures are considered collectively in context with one-another, and that optimally the metrics are monitored through time. This will allow a correct and more nuanced assessment of the current comparative state of the reef along with an indication of the trajectory in which the reef is heading.

The effects of different disturbance types on surface metrics will need further research, however if these factors are appropriately accounted for it may potentially be ultimately be possible to make predictions as to the type of pressure affecting the system just using a suite of measured surface metrics, i.e. high sediment loads would likely be indicated by reduced kurtosis, reduced roughness, and retained height, while heavy blasting would be indicated by increased kurtosis, reduced roughness, and reduced height.

\section{Management implications}

Improved enforcement and compliance through education and engagement around the damaging effects of illegal blast fishing must be the first priority for future effective management of the benthic communities across this area, but it is also recommended that following successful cessation of blast fishing, some method of rubble stabilization be implemented at the Pandanon site (Raymundo et al., 2007). Stabilization is likely to enhance recovery of this reef, which is currently in a highly degraded state even inside some parts of the MPA, by allowing new coral recruits to establish and re-form a permanent reef.

While it is apparent that capacity shortfalls, inappropriate targets and poor monitoring tools are hindering the effective use of MPAs in many countries (Ahmadia et al., 2015; Gill et al., 2017; Parsons, MacPherson, \& Villagomez, 2017), MPA management is still typically shown 
to be a valuable cost-effective tool for producing multiple biological benefits for marine systems across scales (Lester et al., 2009; Roberts et al., 2017), a finding supported by this study. The ability to effectively manage and build reef resources is an important tool within a wider integrated social-ecological system approach. However, such management must be applied in conjunction with the improvement of linked socio-economic factors such as human welfare, institutional capacity, and alternative employment opportunities, if it is to be successful long-term and continue to benefit the surrounding communities (Cinner et al., 2009).

Well maintained reefs and their associated fisheries are integral to the livelihood, shoreline stability and food security of many coastal communities, particularly in lower income countries such as the Philippines (Barbier et al., 2011; Cabral \& Geronimo, 2018; Spalding et al., 2017). Ongoing work to form a Philippine country-wide network of MPAs and to adequately monitor their individual management performances (Anticamara \& Go, 2016; Cabral et al., 2014; Horigue, Aliño, \& Pressey, 2014; Maypa et al., 2012), is therefore extremely important for the proper protection of the reefs and fisheries of this archipelago, which continues to experience a range of pressures as the human population grows (Muallil, Mamauag, Cababaro, Arceo, \& Aliño, 2014; Selgrath et al., 2017). Incorporating new and easy to instigate methods such as SfM photogrammetry could help to feed into this existing monitoring work, particularly as accurately assessing reef structural complexity has been shown to be one of the hardest MPA management effectiveness indicators to assess using traditional methods (Tupper, Asif, Garces, \& Pido, 2015).

As the concept of Ecosystem Based Management (EBM) becomes commonplace in marine systems (Curtin \& Prellezo, 2010), a shift towards the application of adaptive management is recognised as playing an important role in both the design and appraisal of marine reserves (Grafton \& Kompas, 2005). In order to for this type of management to be effective however, continuous monitoring is necessary of multiple components of the ecosystem so that site specific management objectives can be constantly updated according to changing needs, cumulative pressure effects, or dynamic environmental variables (Curtin \& Prellezo, 2010; Long, Charles, \& Stephenson, 2015). Given the speed in which large areas of reef can be assessed for both reef structural complexity and broad substrate cover metrics using this technique, it will likely be a useful and efficient tool for the rapid quantitative data acquisition needed to inform such adaptive management (Bayley et al., 2019). Furthermore the ortho-mosaic outputs can be used as an effective visualisation and engagement tool for stakeholder discussions and decision making, which are integral aspects of the EBM process (Grafton \& Kompas, 2005; Long et al., 2015).

Maintaining the current level of community engagement and management for MPAs would seem critical for the continued health of these reefs into the future (Hind, Hiponia, \& Gray, 2010; Karr et al., 2017; Maliao, Pomeroy, \& Turingan, 2009), but more broadly there is a need for better management of the reefs and fisheries outside of the MPAs too, in order to stop continued reef degradation across the region. Roughly two-thirds of the Philippines' reefs are currently rated as having a high or very high local threat of damage from human impacts, and the country as a whole is in the highest category of dependence on reef resources, and vulnerability to degradation globally (Burke et al., 2012). Without action to limit regional impacts alongside local management, only limited successes can be expected to be achieved. 


\section{Acknowledgements}

Dan Bayley was supported by the Natural Environment Research Council [grant number NE/L002485/1]. Additional funding for software and hardware used in analysis was provided through the NERC Services and Facilities capital equipment scheme. Thanks to the ZSL Philippines team for use of field equipment and site access, as well as to Angelie Nellas, Myrtle Arias, Nicholson Tan and Eduard Alivo for logistic and field assistance, supported by the Waterloo Foundation and Darwin Initiative.

\section{Author contributions}

DB, HK and AP led the conception and design of the work. DB and AM were involved in the acquisition, analysis and interpretation of data. DB drafted the work. HK, AP and AM provided review and revisions of the final work.

\section{Conflict of interest statement}

The submitted work was carried out with the absence of any personal, professional or financial relationships that could be construed as a conflict of interest.

\section{Ethical statement}

Approval and permits to conduct research at each site within each of Bohol's municipality's jurisdiction were obtained from the municipality mayor and the local barangay leaders before surveys took place. No physical samples of fish, benthos or water were taken, therefore no organisms were harmed during this work. 


\section{References}

Agardy, T., di Sciara, G. N., \& Christie, P. (2011). Mind the gap: Addressing the shortcomings of marine protected areas through large scale marine spatial planning. Marine Policy, 35(2), 226232. https://doi.org/10.1016/j.marpol.2010.10.006

Agisoft LLC. (2017). AgiSoft PhotoScan Professional edition (Version 1.3.4). Retrieved from Http://Www.Agisoft.Com/Downloads/Installer/.

Ahmadia, G. N., Glew, L., Provost, M., Gill, D., Hidayat, N. I., Mangubhai, S., ... Fox. (2015). Integrating impact evaluation in the design and implementation of monitoring marine protected areas. Philosophical Transactions of the Royal Society B: Biological Sciences, 370(1681), 20140275. https://doi.org/10.1098/rstb.2014.0275

Alcala, A. C., Bucol, A. A., \& Nillos-kleiven, P. (2008). Directory of marine reserves in the Visanas, Philippines. Silliman Press, Dumaguete City 6200, Philippines.

Alcala, A. C., \& Russ, G. (2002). Status of Philippine coral reef fisheries. Asian Fisheries Science, 15, 177-190. Retrieved from http://eprints.jcu.edu.au/13477

Anderson, K., Westoby, M. J., \& James, M. R. (2019). Low-budget topographic surveying comes of age: Structure from motion photogrammetry in geography and the geosciences. Progress in Physical Geography: Earth and Environment, 43(2), 163-173. https://doi.org/10.1177/0309133319837454

Anderson, M. J., \& Walsh, D. C. I. (2013). Permanova, anosim, Mantel test face heterogeneous dispersions: What null hypothesis are you testing? Ecological Monographs, 83(4), 557-574. https://doi.org/10.1890/12-2010.1

Anticamara, J. A., \& Go, K. T. B. (2016). Spatio-temporal declines in Philippine fisheries and its implications to coastal municipal fishers' catch and income. Frontiers in Marine Science, 3(March), 1-10. https://doi.org/10.3389/fmars.2016.00021

Aston, E. A., Williams, G. J., Green, J. A. M., Davies, A. J., Wedding, L. M., Gove, J. M., ... Clark, J. (2019). Scale-dependent spatial patterns in benthic communities around a tropical island seascape. Ecography, 42(3), 578-590. https://doi.org/10.1111/ecog.04097

Barbier, E. B., Hacker, S. D., Kennedy, C., Koch, E., Stier, A. C., \& Silliman, B. R. (2011). The value of estuarine and coastal ecosystem services. Ecological Monographs, 81(2), 169-193.

Bayley, D. T. I., \& Mogg, A. O. M. (2019). New advances in benthic monitoring technology and methodology. In C. R. C. Sheppard (Ed.), World seas: an environmental evaluation (pp. 121132). Elsevier. https://doi.org/10.1016/B978-0-12-805052-1.00006-1

Bayley, D. T. I., Mogg, A. O. M., Koldewey, H., \& Purvis, A. (2019). Capturing complexity: fieldtesting the use of 'structure from motion' derived virtual models to replicate standard measures of reef physical structure. PeerJ, 7, e6540. https://doi.org/10.7717/peerj.6540

Bergman, M. J. N., Birchenough, S. N. R., Borja, Á., Boyd, S. E., Brown, C. J., Buhl-Mortensen, L., ... De Boois, I. (2009). Guidelines for the study of the epibenthos of subtidal environments. ICES Techniques in Marine Environmental Sciences.

Boettiger, C., Lang, D. T., \& Wainwright, P. C. (2012). Rfishbase: Exploring, manipulating and visualizing FishBase data from R. Journal of Fish Biology, 81(6), 2030-2039. https://doi.org/10.1111/j.1095-8649.2012.03464.x

Bryson, M., Ferrari, R., Figueira, W., Pizarro, O., Madin, J., Williams, S., \& Byrne, M. (2017). Characterization of measurement errors using structure-from-motion and photogrammetry to measure marine habitat structural complexity. Ecology and Evolution, (May), 1-13. https://doi.org/10.1002/ece3.3127 
Burke, L., Reytar, K. K., Spalding, M. D., Perry, A., Knight, M., Kushner, B., ... White, A. (2012). Reefs at risk: Revisited in the coral triangle. Defenders (Vol. 74). https://doi.org/10.1016/00220981(79)90136-9

Burns, J. H. R., Delparte, D., Gates, R., \& Takabayashi, M. (2015). Integrating structure-from-motion photogrammetry with geospatial software as a novel technique for quantifying 3D ecological characteristics of coral reefs. PeerJ, 3, e1077. https://doi.org/10.7717/peerj.1077

Butchart, S. H. M., Walpole, M., Collen, B., van Strien, A., Scharlemann, J. P. W., Almond, R. E. A., ... Watson, R. (2010). Global biodiversity: Indicators of recent declines. Science, 328(5982), 1164-1168. https://doi.org/10.1126/science.1187512

Cabral, R. B., Aliño, P. M., Balingit, A. C. M., Alis, C. M., Arceo, H. O., Jr, C. L. N., ... Partners, M. S. N. (2014). The Philippine Marine Protected Area (MPA) Database. Philippine Science Letters, 7(2), 300-308. Retrieved from http://philsciletters.org/2014/PSL 2014-vol07-no02p300-308 Cabral-Alino.pdf

Cabral, R. B., \& Geronimo, R. C. (2018). How important are coral reefs to food security in the Philippines? Diving deeper than national aggregates and averages. Marine Policy, 91(February), 136-141. https://doi.org/10.1016/j.marpol.2018.02.007

Carboni, N., Bruseker, G., Guillem, A., Bellido Castañeda, D., Coughenour, C., Domajnko, M., ... Suma, R. (2016). Data provenance in photogrammetry through documentation protocols. ISPRS Annals of Photogrammetry, Remote Sensing and Spatial Information Sciences, III-5(July), 5764. https://doi.org/10.5194/isprs-annals-III-5-57-2016

Cinner, J. E., McClanahan, T. R., Daw, T. M., Graham, N. A. J., Maina, J., Wilson, S. K., \& Hughes, T. P. (2009). Linking social and ecological systems to sustain coral reef fisheries. Current Biology, 19(3), 206-212. https://doi.org/10.1016/j.cub.2008.11.055

Clarke, K. R., Chapman, M. G., Somerfield, P. J., \& Needham, H. R. (2006). Dispersion-based weighting of species counts in assemblage analyses. Marine Ecology Progress Series, 320(1), 11-27. https://doi.org/10.3354/meps320011

Clarke, K. R., Somerfield, P. J., \& Chapman, M. G. (2006). On resemblance measures for ecological studies, including taxonomic dissimilarities and a zero-adjusted Bray-Curtis coefficient for denuded assemblages. Journal of Experimental Marine Biology and Ecology, 330(1), 55-80. https://doi.org/10.1016/j.jembe.2005.12.017

Cole, A. J., Pratchett, M. S., \& Jones, G. P. (2008). Diversity and functional importance of coralfeeding fishes on tropical coral reefs. Fish and Fisheries, 9(3), 286-307. https://doi.org/10.1111/j.1467-2979.2008.00290.x

Curtin, R., \& Prellezo, R. (2010). Understanding marine ecosystem based management: A literature review. Marine Policy, 34(5), 821-830. https://doi.org/10.1016/j.marpol.2010.01.003

da Silva, I. M., Hill, N., Shimadzu, H., Soares, A. M. V. M., \& Dornelas, M. (2015). Spillover effects of a community-managed marine reserve. PLOS ONE, 10(4), e0111774. https://doi.org/10.1371/journal.pone.0111774

Darling, E. S., Graham, N. A. J., Januchowski-Hartley, F. A., Nash, K. L., Pratchett, M. S., \& Wilson, S. K. (2017). Relationships between structural complexity, coral traits, and reef fish assemblages. Coral Reefs, 36(2), 561-575. https://doi.org/10.1007/s00338-017-1539-z

Edgar, G. J., Stuart-Smith, R. D., Willis, T. J., Kininmonth, S., Baker, S. C., Banks, S., ... Thomson, R. J. (2014). Global conservation outcomes depend on marine protected areas with five key features. Nature, 506(7487), 216-220. https://doi.org/10.1038/nature13022

Edwards, C. B., Eynaud, Y., Williams, G. J., Pedersen, N. E., Zgliczynski, B. J., Gleason, A. C. R., ... Sandin, S. A. (2017). Large-area imaging reveals biologically driven non-random spatial 
patterns of corals at a remote reef. Coral Reefs, 36(4), 1291-1305. https://doi.org/10.1007/s00338-017-1624-3

Ferrari, R., McKinnon, D., He, H., Smith, R. N., Corke, P., González-Rivero, M., ... Upcroft, B. (2016). Quantifying multiscale habitat structural complexity: A cost-effective framework for underwater 3D modelling. Remote Sensing, 8(2), 113. https://doi.org/10.3390/rs8020113

Figueira, W., Ferrari, R., Weatherby, E., Porter, A., Hawes, S., \& Byrne, M. (2015). Accuracy and precision of habitat structural complexity metrics derived from underwater photogrammetry. Remote Sensing, 7(12), 16883-16900. https://doi.org/10.3390/rs71215859

Fox, H. E., \& Caldwell, R. L. (2006). Recovery from blast fishing on coral reefs: A tale of two scales. Ecological Applications, 16(5), 1631-1635. https://doi.org/10.1890/10510761(2006)016[1631:RFBFOC]2.0.CO;2

Froese, R. (2006). Cube law, condition factor and weight-length relationships: History, meta-analysis and recommendations. Journal of Applied Ichthyology, 22(4), 241-253. https://doi.org/10.1111/j.1439-0426.2006.00805.x

Froese, R., \& Pauly, D. (2018). Fishbase. Retrieved February 1, 2018, from http://www.fishbase.org

Froese, R., Thorson, J. T., \& Reyes, R. B. (2014). A Bayesian approach for estimating length-weight relationships in fishes. Journal of Applied Ichthyology, 30(1), 78-85. https://doi.org/10.1111/jai.12299

Fukunaga, A., Burns, J., Craig, B., \& Kosaki, R. (2019). Integrating Three-Dimensional Benthic Habitat Characterization Techniques into Ecological Monitoring of Coral Reefs. Journal of Marine Science and Engineering, 7(2), 27. https://doi.org/10.3390/jmse7020027

Gill, D. A., Mascia, M. B., Ahmadia, G. N., Glew, L., Lester, S. E., Barnes, M., ... Fox, H. E. (2017). Capacity shortfalls hinder the performance of marine protected areas globally. Nature. https://doi.org/10.1038/nature21708

González-Rivero, M., Harborne, A. R., Herrera-Reveles, A., Bozec, Y. M. Y.-M. Y.-M., Rogers, A., Friedman, A., ... Hoegh-Guldberg, O. (2017). Linking fishes to multiple metrics of coral reef structural complexity using three-dimensional technology. Scientific Reports, 7(1), 13965. https://doi.org/10.1038/s41598-017-14272-5

Grafton, R. Q., \& Kompas, T. (2005). Uncertainty and the active adaptive management of marine reserves. Marine Policy, 29(5), 471-479. https://doi.org/10.1016/j.marpol.2004.07.006

Graham, N. A. J., Jennings, S., MacNeil, M. A., Mouillot, D., \& Wilson, S. K. (2015). Predicting climate-driven regime shifts versus rebound potential in coral reefs. Nature, 518(7537), 1-17. https://doi.org/10.1038/nature14140

Graham, N. A. J., \& Nash, K. L. (2013). The importance of structural complexity in coral reef ecosystems. Coral Reefs, 32(2), 315-326. https://doi.org/10.1007/s00338-012-0984-y

Gutierrez-Heredia, L., Benzoni, F., Murphy, E., \& Reynaud, E. G. (2016). End to End Digitisation and Analysis of Three-Dimensional Coral Models, from Communities to Corallites. PLoS ONE, 11(2). https://doi.org/10.1371/journal.pone.0149641

Halpern, B. S., Frazier, M., Potapenko, J., Casey, K. S., Koenig, K., Longo, C., ... Walbridge, S. (2015). Spatial and temporal changes in cumulative human impacts on the world's ocean. Nature Communications, 6(May), 1-7. https://doi.org/10.1038/ncomms8615

Hargreaves-Allen, V. A., Mourato, S., \& Milner-Gulland, E. J. (2017). Drivers of coral reef marine protected area performance. PLoS ONE, 12(6), e0179394. https://doi.org/10.1371/journal.pone.0179394

Hata, T., Madin, J. S., Cumbo, V. R., Denny, M., Figueiredo, J., Harii, S., ... Baird, A. H. (2017). 
Coral larvae are poor swimmers and require fine-scale reef structure to settle. Scientific Reports, 7(1), 1-9. https://doi.org/10.1038/s41598-017-02402-y

Hind, E. J., Hiponia, M. C., \& Gray, T. S. (2010). From community-based to centralised national management-A wrong turning for the governance of the marine protected area in Apo Island, Philippines? Marine Policy, 34(1), 54-62. https://doi.org/10.1016/j.marpol.2009.04.011

Hoeksema, B. W. (2012). Distribution patterns of mushroom corals (scleractinia: Fungiidae) across the spermonde Shelf, Southsulawesi. Raffles Bulletin of Zoology, 60(1), 183-212.

Horigue, V., Aliño, P. M., \& Pressey, R. L. (2014). Evaluating management performance of marine protected area networks in the Philippines. Ocean \& Coastal Management, 95, 11-25. https://doi.org/10.1016/j.ocecoaman.2014.03.023

House, J. E., Brambilla, V., Bidaut, L. M., Christie, A. P., Pizarro, O., Madin, J. S., \& Dornelas, M. (2018). Moving to 3D: relationships between coral planar area, surface area and volume. PeerJ, 6, e4280. https://doi.org/10.7717/peerj.4280

Hudson, L. N., Newbold, T., Contu, S., Hill, S. L. L., Lysenko, I., De Palma, A., ... Purvis, A. (2014). The PREDICTS database: a global database of how local terrestrial biodiversity responds to human impacts. Ecology and Evolution, 4(24), 4701-4735. https://doi.org/10.1002/ece3.1303

Jamero, M. L., Onuki, M., Esteban, M., Billones-Sensano, X. K., Tan, N., Nellas, A., ... Valenzuela, V. P. (2017). Small-island communities in the Philippines prefer local measures to relocation in response to sea-level rise. Nature Climate Change, 7(8), 581-586. https://doi.org/10.1038/NCLIMATE3344

Kaiser, M. J. (2005). Are Marine Protected Areas a red herring or fisheries panacea? Canadian Journal of Fisheries and Aquatic Sciences, 62(5), 1194-1199. https://doi.org/10.1139/f05-056

Karr, K. A., Fujita, R., Carcamo, R., Epstein, L., Foley, J. R., Fraire-Cervantes, J. A., ... Kritzer, J. P. (2017). Integrating science-based co-management, partnerships, participatory processes and stewardship incentives to improve the performance of small-Scale fisheries. Frontiers in Marine Science, 4(October). https://doi.org/10.3389/fmars.2017.00345

Klapetek, P., Necas, D., \& Anderson, C. (2016). Gwyddion user guide.

Langebrake, J., Riotte-Lambert, L., Osenberg, C. W., \& de Leenheer, P. (2012). Differential movement and movement bias models for marine protected areas. Journal of Mathematical Biology, 64(4), 667-696. https://doi.org/10.1007/s00285-011-0407-7

Lavy, A., Eyal, G., Neal, B., Keren, R., Loya, Y., \& Ilan, M. (2015). A quick, easy and non-intrusive method for underwater volume and surface area evaluation of benthic organisms by 3D computer modelling. Methods in Ecology and Evolution, 6(5), 521-531. https://doi.org/10.1111/2041-210X.12331

Lea, J. S. E., Humphries, N. E., von Brandis, R. G., Clarke, C. R., \& Sims, D. W. (2016). Acoustic telemetry and network analysis reveal the space use of multiple reef predators and enhance marine protected area design. Proceedings of the Royal Society B: Biological Sciences, 283(1834), 20160717. https://doi.org/10.1098/rspb.2016.0717

Legendre, P., \& Andersson, M. J. (1999). Distance-based redundancy analysis: Testing multispecies responses in multifactorial ecological experiments. Ecological Monographs, 69(1), 1-24. https://doi.org/10.1890/0012-9615(1999)069[0001:DBRATM]2.0.CO;2

Lester, S., Halpern, B., Grorud-Colvert, K., Lubchenco, J., Ruttenberg, B., Gaines, S., ... Warner, R. (2009). Biological effects within no-take marine reserves: a global synthesis. Marine Ecology Progress Series, 384, 33-46. https://doi.org/10.3354/meps08029

Long, R. D., Charles, A., \& Stephenson, R. L. (2015). Key principles of marine ecosystem-based 
management. Marine Policy, 57, 53-60. https://doi.org/10.1016/j.marpol.2015.01.013

Luckhurst, B. E., \& Luckhurst, K. (1978). Analysis of the influence of substrate variables on coral reef fish communities. Marine Biology, 49(4), 317-323. https://doi.org/10.1007/BF00455026

Magdaong, E. T., Fujii, M., Yamano, H., Licuanan, W. Y., Maypa, A., Campos, W. L., ... Martinez, R. (2014). Long-term change in coral cover and the effectiveness of marine protected areas in the Philippines: A meta-analysis. Hydrobiologia, 733(1), 5-17. https://doi.org/10.1007/s10750013-1720-5

Maliao, R. J., Pomeroy, R. S., \& Turingan, R. G. (2009). Performance of community-based coastal resource management (CBCRM) programs in the Philippines: A meta-analysis. Marine Policy, 33(5), 818-825. https://doi.org/10.1016/j.marpol.2009.03.003

Marinesque, S., Kaplan, D. M., \& Rodwell, L. D. (2012). Global implementation of marine protected areas: Is the developing world being left behind? Marine Policy, 36(3), 727-737. https://doi.org/10.1016/j.marpol.2011.10.010

Maxwell, S. L., Fuller, R. A., Brooks, T. M., \& Watson, J. E. M. (2016). Biodiversity: The ravages of guns, nets and bulldozers. Nature, 536(7615), 143-145. https://doi.org/10.1038/536143a

Maypa, A. P., White, A. T., Caňares, E., Martinez, R., Eisma-Osorio, R. L., Aliňo, P., \& Apistar, D. (2012). Marine protected area management effectiveness: progress and lessons in the Philippines. Coastal Management, 40(5), 510-524. https://doi.org/10.1080/08920753.2012.709465

McClanahan, T. R., Marnane, M. J., Cinner, J. E., \& Kiene, W. E. (2006). A comparison of Marine Protected Areas and alternative approaches to coral-reef management. Current Biology, 16(14), 1408-1413. https://doi.org/10.1016/j.cub.2006.05.062

Mora, C., Aburto-Oropeza, O., Ayala Bocos, A., Ayotte, P. M., Banks, S., Bauman, A. G., ... Zapata, F. a. (2011). Global Human Footprint on the Linkage between Biodiversity and Ecosystem Functioning in Reef Fishes. PLoS Biology, 9(4), e1000606. https://doi.org/10.1371/journal.pbio.1000606

Mora, C., Andrèfouët, S., Costello, M. J., Kranenburg, C., Rollo, A., Veron, J., ... Myers, R. A. (2006). Coral reefs and the global network of Marine Protected Areas. Science, 312(5781), 1750-1751. https://doi.org/10.1126/science.1125295

Mouillot, D., Parravicini, V., Bellwood, D. R., Leprieur, F., Huang, D., Cowman, P. F., ... Guilhaumon, F. (2016). Global marine protected areas do not secure the evolutionary history of tropical corals and fishes. Nature Communications, 7(May 2015), 10359. https://doi.org/10.1038/ncomms10359

Muallil, R. N., Mamauag, S. S., Cababaro, J. T., Arceo, H. O., \& Aliño, P. M. (2014). Catch trends in Philippine small-scale fisheries over the last five decades: The fishers perspectives. Marine Policy, 47, 110-117. https://doi.org/10.1016/j.marpol.2014.02.008

Musick, J. A. (1999). Criteria to define extinction risk in marine fishes: the American Fisheries Society Initiative. Fisheries, 24(12), 6-14. https://doi.org/10.1577/15488446(1999)024<0006:CTDERI>2.0.CO;2

Nash, K. L., Graham, N. A. J., Wilson, S. K., \& Bellwood, D. R. (2013). Cross-scale habitat structure drives fish body size distributions on coral reefs. Ecosystems, 16(3), 478-490. https://doi.org/10.1007/s10021-012-9625-0

Nečas, D., \& Klapetek, P. (2012). Gwyddion: an open-source software for SPM data analysis. Open Physics, 10(1). https://doi.org/10.2478/s11534-011-0096-2

O’Leary, B. C., Winther-Janson, M., Bainbridge, J. M., Aitken, J., Hawkins, J. P., \& Roberts, C. M. 
(2016). Effective Coverage Targets for Ocean Protection. Conservation Letters, 9(6), 398-404. https://doi.org/10.1111/conl.12247

Oksanen, J., Blanchet, G., Friendly, M., Kindt, R., Legendre, P., McGlinn, D., ... Wagner, H. (2017). Vegan: Community ecology package. Retrieved from https://cran.r-project.org/package=vegan

Osenberg, C., Shima, J., Miller, S. L., \& Stier, A. C. (2011). Assessing effects of marine protected areas: confounding in space and possible solutions. (J. Claudet, Ed.), Marine Protected Areas: A multidisiplinary approach. Cambridge University Press, UK.

Parsons, E. C. M., MacPherson, R., \& Villagomez, A. (2017). Marine "conservation": you keep using that word but I don't think it means what you think it means. Frontiers in Marine Science, 4(September). https://doi.org/10.3389/fmars.2017.00299

Paulay, G. (1997). Life and Death of Coral Reefs. (C. Birkeland, Ed.). Boston, MA: Springer US. https://doi.org/10.1007/978-1-4615-5995-5

Perry, C. T., Alvarez-Filip, L., Graham, N. A. J., Mumby, P. J., Wilson, S. K., Kench, P. S., ... Macdonald, C. (2018). Loss of coral reef growth capacity to track future increases in sea level. Nature, 558(7710), 396-400. https://doi.org/10.1038/s41586-018-0194-z

Pimm, S. L. (2001). Can we defy nature's end? Science, 293(5538), 2207-2208. https://doi.org/10.1126/science.1061626

Pratchett, M. S., Hoey, A. S., Wilson, S. K., Messmer, V., \& Graham, N. A. J. (2011). Changes in biodiversity and functioning of reef fish assemblages following coral bleaching and coral loss. Diversity, 3(3), 424-452. https://doi.org/10.3390/d3030424

R Core Team. (2016). R: A Language and Environment for Statistical Computing. Vienna, Austria. Retrieved from https://www.r-project.org/

Raoult, V., David, P. A., Dupont, S. F., Mathewson, C. P., O’Neill, S. J., Powell, N. N., \& Williamson, J. E. (2016). GoPros ${ }^{\mathrm{TM}}$ as an underwater photogrammetry tool for citizen science. PeerJ, 4, e1960. https://doi.org/10.7717/peerj.1960

Raoult, V., Reid-Anderson, S., Ferri, A., \& Williamson, J. (2017). How reliable is Structure from Motion (SfM) over time and between observers? A case study using coral reef bommies. Remote Sensing, 9(7), 740. https://doi.org/10.3390/rs9070740

Raymundo, L. J., Maypa, A. P., Gomez, E. D., \& Cadiz, P. (2007). Can dynamite-blasted reefs recover? A novel, low-tech approach to stimulating natural recovery in fish and coral populations. Marine Pollution Bulletin, 54(7), 1009-1019. https://doi.org/10.1016/j.marpolbul.2007.02.006

Richardson, L. E., Graham, N. A. J., \& Hoey, A. S. (2017). Cross-scale habitat structure driven by coral species composition on tropical reefs. Scientific Reports, 7(1), 7557. https://doi.org/10.1038/s41598-017-08109-4

Riegl, B., Bruckner, A., Coles, S. L., Renaud, P., \& Dodge, R. E. (2009). Coral reefs: Threats and conservation in an era of global change. Annals of the New York Academy of Sciences, 1162, 136-186. https://doi.org/10.1111/j.1749-6632.2009.04493.x

Roberts, C. M., O’Leary, B. C., McCauley, D. J., Cury, P. M., Duarte, C. M., Lubchenco, J., ... Castilla, J. C. (2017). Marine reserves can mitigate and promote adaptation to climate change. Proceedings of the National Academy of Sciences, 114(24), 6167-6175. https://doi.org/10.1073/pnas.1701262114

Russ, G., Miller, K., Rizzari, J., \& Alcala, A. (2015). Long-term no-take marine reserve and benthic habitat effects on coral reef fishes. Marine Ecology Progress Series, 529, 233-248. https://doi.org/10.3354/meps11246 
Samoilys, M. a., Martin-Smith, K. M., Giles, B. G., Cabrera, B., Anticamara, J. a., Brunio, E. O., \& Vincent, A. C. J. (2007). Effectiveness of five small Philippines' coral reef reserves for fish populations depends on site-specific factors, particularly enforcement history. Biological Conservation, 136(4), 584-601. https://doi.org/10.1016/j.biocon.2007.01.003

Sciberras, M., Jenkins, S. R., Kaiser, M. J., Hawkins, S. J., \& Pullin, A. S. (2013). Evaluating the biological effectiveness of fully and partially protected marine areas. Environmental Evidence, 2(1), 1-31. https://doi.org/10.1186/2047-2382-2-4

Selgrath, J. C., Gergel, S. E., \& Vincent, A. C. J. (2017). Incorporating spatial dynamics greatly improves estimates of fishing pressure: Long-term participatory mapping of coral reef fisheries. ICES Journal of Marine Science, (January), 1-11. https://doi.org/10.1093/icesjms/fsx226

Simpson, S. D. (2005). Homeward Sound. Science, 308(5719), 221-221. https://doi.org/10.1126/science.1107406

Singleton, R. L., \& Roberts, C. M. (2014). The contribution of very large marine protected areas to marine conservation: Giant leaps or smoke and mirrors? Marine Pollution Bulletin, 87(1-2), 7 10. https://doi.org/10.1016/j.marpolbul.2014.07.067

Spalding, M., Burke, L., Wood, S. A., Ashpole, J., Hutchison, J., \& zu Ermgassen, P. (2017). Mapping the global value and distribution of coral reef tourism. Marine Policy, 82(May), 104113. https://doi.org/https://doi.org/10.1016/j.marpol.2017.05.014

Tamayo, N. C. A., Anticamara, J. A., \& Acosta-Michlik, L. (2018). National estimates of values of Philippine reefs' ecosystem services. Ecological Economics, 146(January 2017), 633-644. https://doi.org/10.1016/j.ecolecon.2017.12.005

Thomas, H. L., Macsharry, B., Morgan, L., Kingston, N., Moffitt, R., Stanwell-Smith, D., \& Wood, L. (2014). Evaluating official marine protected area coverage for Aichi Target 11: Appraising the data and methods that define our progress. Aquatic Conservation: Marine and Freshwater Ecosystems, 24(S2), 8-23. https://doi.org/10.1002/aqc.2511

Tupper, M., Asif, F., Garces, L. R., \& Pido, M. D. (2015). Evaluating the management effectiveness of marine protected areas at seven selected sites in the Philippines. Marine Policy, 56, 33-42. https://doi.org/10.1016/j.marpol.2015.02.008

Turnbull, J. W., Shah Esmaeili, Y., Clark, G. F., Figueira, W. F., Johnston, E. L., \& Ferrari, R. (2018). Key drivers of effectiveness in small marine protected areas. Biodiversity and Conservation. https://doi.org/10.1007/s10531-018-1532-z

Westoby, M. J., Brasington, J., Glasser, N. F., Hambrey, M. J., \& Reynolds, J. M. (2012). 'Structurefrom-Motion' photogrammetry: A low-cost, effective tool for geoscience applications. Geomorphology, 179, 300-314. https://doi.org/10.1016/j.geomorph.2012.08.021

White, A., Alino, P., \& Meneses, A. (2006). Creating and managing marine protected areas in the Philippines (Vol. 83). Philippines Marine Science Institute, Cebu City, Philippines. Retrieved from http://www.ncbi.nlm.nih.gov/entrez/query.fcgi?db=pubmed\&cmd=Retrieve\&dopt=AbstractPlus \&list_uids=17721433427093658274related:opqmTM8t7_UJ

Wilson, S. K., Graham, N. A. J., \& Polunin, N. V. C. (2007). Appraisal of visual assessments of habitat complexity and benthic composition on coral reefs. Marine Biology, 151(3), 1069-1076. https://doi.org/10.1007/s00227-006-0538-3

Yasué, M., Nellas, A., \& Vincent, A. C. J. (2012). Seahorses helped drive creation of marine protected areas, so what did these protected areas do for the seahorses? Environmental Conservation, 39(2), 183-193. https://doi.org/10.1017/S0376892911000622 
